OPEN ACCESS

Edited by:

Paula Gomes,

University of Porto, Portugal

Reviewed by:

Hong Yao,

Fujian Medical University, China

Pukar Khanal,

KLE College of Pharmacy, India

*Correspondence:

Aiguo $\mathrm{Li}$

Liaiguo7161@ext.jnu.edu.cn

Yanhua Wu

wuyanhua368@163.com

Zhihe Liu

zliu0731@ext.jnu.edu.cn

${ }^{+}$These authors have contributed equally to this work

Specialty section:

This article was submitted to

Experimental Pharmacology and Drug

Discovery,

a section of the journa

Frontiers in Pharmacology

Received: 02 September 2021 Accepted: 02 December 2021

Published: 22 December 2021

Citation:

Xiong $X$, Tang N, Lai X, Zhang J, Wen W, Li X, Li A, WU Y and LiU Z (2021) Insights Into Amentoflavone: $A$

Natural Multifunctional Biflavonoid.

Front. Pharmacol. 12:768708.

doi: 10.3389/fphar.2021.768708

\section{Insights Into Amentoflavone: A Natural Multifunctional Biflavonoid}

\author{
Xifeng Xiong ${ }^{1 \dagger}$, Nan Tang ${ }^{2 \dagger}$, Xudong Lai ${ }^{3 \dagger}$, Jinli Zhang ${ }^{1}$, Weilun Wen ${ }^{2}$, Xiaojian $\mathrm{Li}^{4}$, Aiguo $\mathrm{Li}^{1 *}$, \\ Yanhua $\mathrm{Wu}^{2 *}$ and Zhihe $\mathrm{Liu}^{1 *}$ \\ ${ }^{1}$ Guangzhou Institute of Traumatic Surgery, Guangzhou Red Cross Hospital, Jinan University, Guangzhou, China, ${ }^{2}$ Department of \\ Traditional Chinese Medicine, Guangzhou Red Cross Hospital, Jinan University, Guangzhou, China, ${ }^{3}$ Department of Infectious \\ Disease, Guangzhou Red Cross Hospital, Jinan University, Guangzhou, China, ${ }^{4}$ Department of Burn and Plastic Surgery, \\ Guangzhou Red Cross Hospital, Jinan University, Guangzhou, China
}

Amentoflavone is an active phenolic compound isolated from Selaginella tamariscina over 40 years. Amentoflavone has been extensively recorded as a molecule which displays multifunctional biological activities. Especially, amentoflavone involves in anti-cancer activity by mediating various signaling pathways such as extracellular signal-regulated kinase (ERK), nuclear factor kappa-B (NF-kB) and phosphoinositide 3-kinase/protein kinase $\mathrm{B}$ (PI3K/AKt), and emerges anti-SARS-CoV-2 effect via binding towards the main protease (Mpro/3CLpro), spike protein receptor binding domain (RBD) and RNAdependent RNA polymerase (RdRp) of SARS-CoV-2. Therefore, amentoflavone is considered to be a promising therapeutic agent for clinical research. Considering the multifunction of amentoflavone, the current review comprehensively discuss the chemistry, the progress in its diverse biological activities, including anti-inflammatory, anti-oxidation, anti-microorganism, metabolism regulation, neuroprotection, radioprotection, musculoskeletal protection and antidepressant, specially the fascinating role against various types of cancers. In addition, the bioavailability and drug delivery of amentoflavone, the molecular mechanisms underlying the activities of amentoflavone, the molecular docking simulation of amentoflavone through in silico approach and antiSARS-CoV-2 effect of amentoflavone are discussed.

Keywords: amentoflavone, anti-cancer, anti-SARS-CoV-2, biological activity, drug delivery, molecular target

\section{INTRODUCTION}

Amentoflavone (AMF, Figure 1), a natural biflavonoid compound, is widely used in traditional Chinese medicine. AMF is initially isolated from the leaves of Selaginella tamariscina, Selaginella rupestris and Ginkgo biloba by Okigawa et al. (1971), Chakravarthy et al. (1981) and Lobstein-Guth et al. (1988). After that, AMF is also successively extracted from more than 120 plants (Yu et al., 2017) such as Celaenodendron mexicanum, Cupressus funebris, Garcinia multiflora, Biophytum sensitivum, Rhus succedanea, Hypericum perforatum, Cupressocyparis leylandii (Lin et al., 1997; KrauzeBaranowska et al., 1999; Camacho et al., 2000; Jurgenliemk and Nahrstedt, 2002). AMF has been shown to exhibit multiple biological activities including anti-inflammatory (Tordera et al., 1994; Kim et al., 1998; Oh et al., 2013; An et al., 2016; Cai et al., 2019), antibacterial (Hwang et al., 2013), antifungal (Jung et al., 2006; Jung et al., 2007; Hwang et al., 2012), antivirus (Lin et al., 1997; Wilsky et al., 2012; Coulerie et al., 2013), anti-oxidative (Bonacorsi et al., 2012; Li et al., 2020), antiangiogenesis (Guruvayoorappan and Kuttan, 2008c; Tarallo et al., 2011; Zhang et al., 2014), neuroprotection (Cao et al., 2017; Chen et al., 2018; Rong et al., 2019; Zhao et al., 2019; Cao 
et al., 2021), osteogenesis (Zha et al., 2016), anti-arthritis (Bais et al., 2017; Vasconcelos et al., 2019), radioprotection (Park et al., 2011; Xu et al., 2014; Qu et al., 2019), antidiabetic (Qin et al., 2018; Su et al., 2019) and antidepressant (Ishola et al., 2012). It is reported that AMF exerts anti-cancer activity through a variety of mechanisms (Guruvayoorappan and Kuttan, 2007; Lee et al., 2011; Pei et al., 2012; Zheng et al., 2016; Liu et al., 2017a; Pan et al., 2017; Chiang et al., 2019; Hsu et al., 2019; Park and Kim, 2019; Chen et al., 2020b). In this review, the biological activities of AMF will be discussed comprehensively.

\section{CHEMISTRY OF AMENTOFLAVONE}

AMF, also to be known as $3^{\prime}, 8^{\prime \prime}$-biapigenin, belongs to the class of biflavonoids and polyflavonoids, one of organic compounds which abundantly exist in Selaginella tamariscina (Selaginellaceae family) with $\mathrm{C}_{30} \mathrm{H}_{18} \mathrm{O}_{10}$ molecular formula and a molecular weight of $538.46 \mathrm{~g} / \mathrm{mol}$. The international union of pure and applied chemistry (IUPAC) name of AMF is $\quad 8$-(5-(5,7-dihydroxy-4-oxo-4H-chromen-2-yl)-2hydroxyphenyl)-5,7-dihydroxy-2-(4-hydroxyphenyl)-4H-

chromen-4-one. A registry number of the Chemical Abstracts Service (CAS) is 1617-53-4. AMF possesses a dimer of two apigenins with six hydroxyl groups on $\mathrm{C} 5, \mathrm{C} 7, \mathrm{C} 4$ ', C5", C7", and C4"' positions (Yu et al., 2017). Thus, AMF is considered to be a flavonoid lipid molecule and is a very hydrophobic molecule, practically insoluble in water $\left(0.0072 \mathrm{~g} / \mathrm{L}\right.$ at $\left.25^{\circ} \mathrm{C}\right)$ and relatively neutral, but easily soluble in alcohol and DMSO (https://hmdb. $\mathrm{ca} /$ metabolites/HMDB0030832). The melting point of AMF is $300^{\circ} \mathrm{C}$. The $2 \mathrm{D}$ and $3 \mathrm{D}$ structures of AMF are shown in Figure 1 (https://pubchem.ncbi.nlm.nih.gov/compound/5281600).

\section{THE MULTIFUNCTIONAL BIOLOGICAL ACTIVITIES OF AMENTOFLAVONE}

As a natural biflavonoid compound, AMF is reported to play various pharmacological effects such as anti-inflammatory (Tordera et al., 1994; Kim et al., 1998; Woo et al., 2005; Huang et al., 2012; Jeong et al., 2012; Ishola et al., 2013; Oh et al., 2013; Sakthivel and Guruvayoorappan, 2013; An et al., 2016; Trang et al., 2016; Zong and Zhang, 2017; Cai et al., 2019; Kuo et al., 2019; Alkadi et al., 2021), anti-microorganism (Lin et al., 1997; Ma et al., 2001; Jung et al., 2006; Jung et al., 2007; Ryu et al., 2010; Hwang et al., 2012; Wilsky et al., 2012; Coulerie et al., 2013; Hwang et al., 2013; Yin et al., 2014; Zhao et al., 2017b; Shen et al., 2018; Bajpai et al., 2019; Liu et al., 2020a), anti-oxidant (Bonacorsi et al., 2012; Li et al., 2020), anti-angiogenesis (Kang et al., 2004; Dell'Agli et al., 2006; Guruvayoorappan and Kuttan, 2008c; Tarallo et al., 2011; Zhang et al., 2014), neuroprotective (Kang et al., 2005; Shin et al., 2006; Zhang et al., 2015; Cao et al., 2017; Chen et al., 2018; Rong et al., 2019; Zhao et al., 2019; Liu et al., 2020b; Choi et al., 2020; Sun et al., 2020; Cao et al., 2021), musculoskeletal protection (Lee et al., 2006; Zha et al., 2016; Bais et al., 2017; Zhang et al., 2018; Vasconcelos et al., 2019), radioprotection (Lee et al., 2008; Park et al., 2011; Lee et al.,
2012; Xu et al., 2014; Qu et al., 2019), metabolism regulation ( $\mathrm{Na}$ et al., 2007; Chen et al., 2016; Yao et al., 2016; Qin et al., 2018; Su et al., 2019; Zhang et al., 2019), anxiolytic/antidepressant (Ishola et al., 2012) and anti-cancer (Banerjee et al., 2002b; Guruvayoorappan and Kuttan, 2007; Lee et al., 2009; Lee et al., 2011; Zheng et al., 2016; Liu et al., 2017a; Pan et al., 2017; Yen et al., 2018; Chiang et al., 2019; Chen et al., 2020b), etc. In addition to the anti-oxidant effect, it has also been reported that AMF can promote oxidation (Wahyudi et al., 2018). The multifunctional biological activities of AMF are detailed in Table 1.

\subsection{Anti-inflammatory Activity}

Inflammation is a natural defense mechanism that protects the human body from a variety of infections (Ellis, 2001). However, the development of inflammatory diseases such as bronchitis, gastritis, enteritis, rheumatoid arthritis and psoriasis is often caused by chronic inflammation (Kaplanski et al., 2003). Kinds of diseases have been attempted to be treated by flavonoids as an anti-inflammation agent. Tordera et al. (1994) demonstrate that the anti-inflammatory activity of AMF can affect neutrophil function through inhibiting $\beta$-glucuronidase and lysozyme basal release in rat neutrophils. AMF also shows a potential anti-inflammatory activity through the inhibition on activities of group II phospholipase A2 and cyclooxygenase in the rat carrageenan paw edema model (Kim et al., 1998). AMF treatment decreases the inflammatory activation of mouse microglial cells after hypoxic-ischeamic (H-I) injury (Shin et al., 2006). AMF could ameliorate IMQ-induced psoriasis-like skin lesion in mice by decreasing NF-kB-mediated inflammation and keratinocyte proliferation (An et al., 2016). In addition, AMF shows antiinflammatory activity via suppressing LPS-induced NO and PGE2, the inhibition of iNOS and COX-2 expression, and the inhibition of NF- $\kappa \mathrm{B}$ signaling pathway in macrophages (Woo et al., 2005; Hammer et al., 2007; Huang et al., 2012; Jeong et al., 2012; Tsai et al., 2012; Oh et al., 2013; Trang et al., 2016; Li et al., 2019b; Kuo et al., 2019). AMF significantly attenuates LPSinduced nitrite release, ROS, MDA formation and TNF-a generation and also upregulates the level of GSH on C6 and THP-1 cells (Ishola et al., 2013; Alkadi et al., 2021). AMF can ameliorate the inflammatory response to cold exposurestimulated lung tissue by inhibition of C3, HMGB1 and BCR/ NF- $\kappa B$ signaling pathway (Cai et al., 2019).

\subsection{Anti-Microorganism Activity}

Infectious disease caused by pathogenic microorganisms affects millions of people worldwide (Hwang et al., 2013). Several studies have reported that AMF is a new strategy for treating microorganism infections, including antiviral (Ma et al., 2001), antifungal (Jung et al., 2006), anti-bacterial (Zhao et al., 2017b) and antileishmanial activity (Rizk et al., 2014; Rizk et al., 2021).

Upper respiratory infection is a common disease worldwide, which is majorly caused by respiratory syncytial virus (RSV) (Borchers et al., 2013). Ma et al. (2001) report that AMF shows potent antiviral activity against RSV, with an $\mathrm{IC}_{50}$ of $5.5 \mathrm{mg} / \mathrm{ml}$. Besides that, it is reported that AMF has antiviral activity against Coxsackievirus B3 (Wilsky et al., 2012; Yin et al., 2014), Dengue 


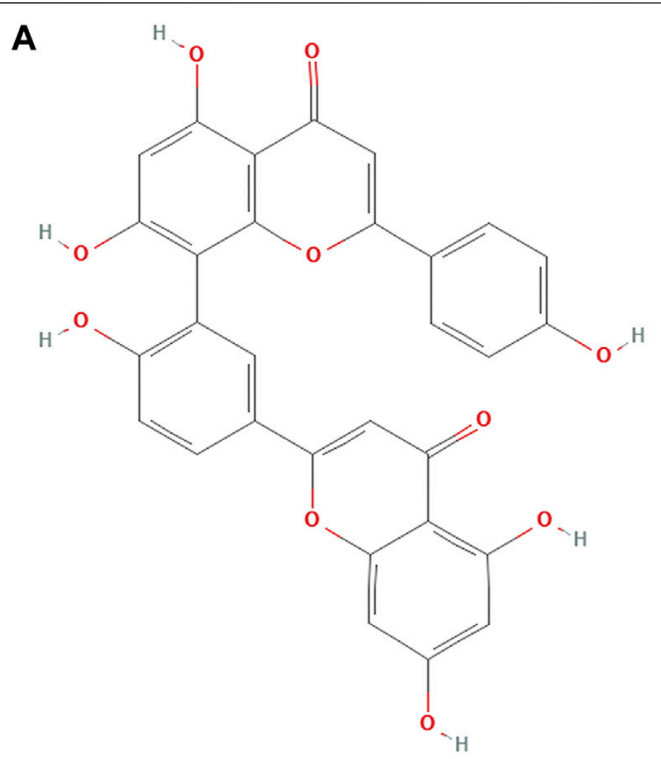

2D structure of AMF
B

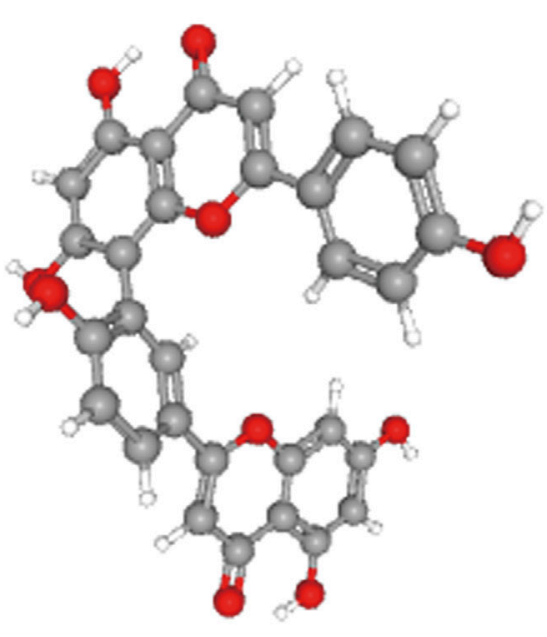

3D structure of AMF

FIGURE 1 | Structure of AMF. (A) 2D structure of AMF; (B) 3D structure of AMF.

virus (Coulerie et al., 2013), Hepatitis C virus (HCV) (Lee et al., 2018c), Herpes Simplex Virus type 1 (HSV-1) (Li et al., 2019a), and SARS-CoV (Ryu et al., 2010). Wilsky et al. (2012) demonstrate that CVB3 infection induces an up-regulation of FAS expression, while the inhibition of FAS expression by AMF inhibits CVB3 replication in human Raji cells. Yin et al. (2014) find that AMF prevents the cytopathic effect (CPE) of CVB3 in HEp-2 cells, and significantly reduces mean viral titers in the heart and kidney which are infected with CVB3 in KM mice. Dengue virus is a prevalent human pathogenic arbovirus (WHO, 2009), the non-structural protein NS5 of which is essential for virus replication (Masse et al., 2010). Coulerie et al. (2013) demonstrate that AMF was a strong and specific noncytotoxic inhibitor of the Dengue virus NS5 RNA-dependent RNA polymerase (DENV-NS5 RdRp). Hepatitis C virus (HCV) is recognized as a major causative agent of chronic hepatitis, cirrhosis, and hepatocellular carcinoma (Kuo et al., 1989). Lee et al. (2018c) identify that AMF inhibited viral entry, replication, and translation of the HCV life cycle, and also exhibits inhibitory effects on resistant-associated variants to the NS5A inhibitor daclatasvir. Herpes Simplex Virus type 1 (HSV-1) is a DNA virus and belongs to a subfamily herpesviridae, which can cause many clinical disorders (i.e., keratitis and encephalitis) (Widener and Whitley, 2014). Li et al. (2019a) reveal that the anti-herpes viral activity of AMF toward HSV-1 and ACV-resistant strains mainly impairs HSV-1 early infection. Furthermore, AMF affects cofilin-mediated F-actin reorganization, decreases the cell membrane transport to the nucleus of HSV-1, and reduces of viral-immediate genes transcription (Li et al., 2019a). SARS-CoV, a positive-strand RNA virus, encodes a chymotrypsin-like protease (3CLpro), which plays a pivotal role in controlling replicase complex activity and processing viral polyproteins
(Anand et al., 2003). Ryu et al. (2010) confirm that AMF is an effective inhibitor of SARS-CoV 3CLpro.

Also, AMF exhibits potent antifungal activity in energyindependent manner by significantly arresting cell cycles at S-phase in human pathogenic fungi C. albicans (Jung et al., 2006; Jung et al., 2007). As well as Jung's results, Hwang et al. (2012) demonstrate that promoting programmed cell death is one antifungal mechanism of AMF in $C$. albicans through mitochondrial dysfunction including phosphatidylserine exposure, DNA and nuclear fragmentation, intracellular ROS accumulation, and metacaspases activities. In addition, AMF reduced mitochondrial inner-membrane potential and induced cyto-c releases (Hwang et al., 2012).

The findings of plenty researches support that AMF has considerable antibacterial activity against $S$. pneumoniae, $S$. suis, M. aeruginosa, S. aureus and E. coli. S. pneumoniae is well known as a human bacterial pathogen (Jedrzejas, 2001). As a devastating protein toxin, pneumolysin (PLY) from streptococcus pneumoniae punctures the cytomembrane and leads to pathological reactions such as cell disruption and inflammation (Zhao et al., 2017b). Zhao et al. (2017b) demonstrate that AMF can weaken the PLY oligomerization process by interacting with Ser254, Glu277, Arg359 sites of the toxin and confer protection against PLY-mediated injury to human alveolar epithelial cells. Streptococcus suis is an important zoonotic pathogen and can lead to considerable economic losses in the swine industry (Haas and Grenier, 2018). Suilysin (SLY) is a secreted extracellular pore-forming toxin which can cause necrosis, apoptosis and cell lysis in various host cells (Fittipaldi et al., 2012). AMF effectively inhibits SLY oligomerization and reduces $S$. suis-induced cytotoxicity in macrophages. Additionally, AMF reduced inflammation in $S$. 
TABLE 1 | The mutiple biological activities of AMF.

\begin{tabular}{|c|c|c|c|c|}
\hline Category & Models & Doses & Biological activities & References \\
\hline \multirow[t]{14}{*}{ Anti-inflammation } & Rats' neutrophils & $\begin{array}{l}4.5 \pm 0.1 \times 10^{-5} \mathrm{M}, 6.2 \pm \\
0.4 \times 10^{-4} \mathrm{M}\end{array}$ & $\beta$-glucuronidase $\downarrow$, Lysozyme release $\downarrow$ & Tordera et al. (1994) \\
\hline & Rat carrageenan paw edema model & $42 \mathrm{mg} / \mathrm{kg}$ & $\begin{array}{l}\text { Group II phospholipase A2 } \downarrow \text {, } \\
\text { Cyclooxygenase } \downarrow\end{array}$ & Kim et al. (1998) \\
\hline & LPS-induced RAW264.7 cells & $0-200 \mu \mathrm{M}$ & $\begin{array}{l}\mathrm{NO} \downarrow, \mathrm{PGE} 2 \downarrow, \mathrm{c}-\mathrm{FOS} \downarrow, \mathrm{AP}-1 \downarrow, \mathrm{ERK} \downarrow \text {, iNOS } \downarrow \text {, } \\
\mathrm{TNF}-\alpha \downarrow, \mathrm{COX}-2 \downarrow, \mid \mathrm{L}-1 \beta \downarrow\end{array}$ & Oh et al. (2013) \\
\hline & IMQ psoriasis-like mice; HaCaT cells & $\begin{array}{l}25 \mathrm{mg} / \mathrm{kg}, 50 \mathrm{mg} / \mathrm{kg} \\
10-20 \mu \mathrm{g} / \mathrm{ml}\end{array}$ & $\begin{array}{l}\text { TNF- } a \downarrow, I L-17 \downarrow, \| L-22 \downarrow, \mid L-23 \downarrow \text {, Cyclin D1 } \\
\text { Cyclin } E \downarrow, N F-\kappa B \text { p65 }\end{array}$ & An et al. (2016) \\
\hline & SD rats & 15 mg/kg, 30 mg/kg & $\begin{array}{l}\text { C3 } 3 \text {, BCR/NF- } \mathrm{kB} \text { signaling pathway } \downarrow \text {, } \\
\mathrm{HMGB} 1 \downarrow\end{array}$ & Cai et al. (2019) \\
\hline & LPS-induced RAW264.7 cells & $3,10,30$ and $60 \mu \mathrm{M}$ & iNOS $\downarrow, N F-\kappa B$ p65 $\downarrow$, l-кBa degradation $\downarrow$ & Woo et al. (2005) \\
\hline & LPS-induced RAW264.7 cells & 1,10 and $100 \mu \mathrm{M}$ & $\mathrm{NO} \downarrow$ & Jeong et al. (2012) \\
\hline & LPS-induced RAW264.7 cells & $0.03 \mu \mathrm{M}$ & 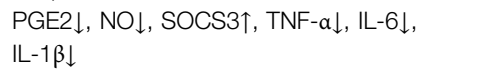 & Huang et al. (2012) \\
\hline & Rats with ulcerative colitis & $10 \mathrm{mg} / \mathrm{kg}$ & 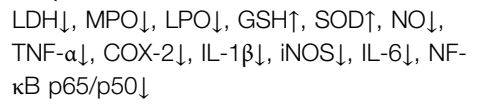 & $\begin{array}{l}\text { Sakthivel and } \\
\text { Guruvayoorappan, } \\
\text { (2013) }\end{array}$ \\
\hline & $\begin{array}{l}\text { LPS-induced C6 cells, LPS-induced THP- } \\
1 \text { cells, SD rats }\end{array}$ & $\begin{array}{l}0.1-3 \mu \mathrm{g} / \mathrm{ml} \\
6.25-50 \mathrm{mg} / \mathrm{kg}\end{array}$ & $\begin{array}{l}\text { Nirtite release } \downarrow, \text { ROS } \downarrow \text {, MDA } \downarrow \text {, TNF- } \alpha \downarrow \text {, } \\
\text { GSH } \uparrow \text {, Reduce number of writhes, Increase } \\
\text { pain threshold, Decrease oedema formation }\end{array}$ & Ishola et al. (2013) \\
\hline & $\begin{array}{l}\text { LPS-stimulated BV2 cells, LPS-stimulated } \\
\text { RAW264.7 cells }\end{array}$ & $\begin{array}{l}\mathrm{IC}_{50}: 12.4 \pm 2.1 \mu \mathrm{M}(\mathrm{BV} 2 \\
\text { cells); } 19.8 \pm 3.3 \mu \mathrm{M} \\
\text { (RAW264.7 cells) }\end{array}$ & $\mathrm{NO} \downarrow$ & Trang et al. (2016) \\
\hline & CLP-induced septic rats & $50 \mathrm{mg} / \mathrm{kg}$ & $\begin{array}{l}\text { TNF- } \alpha \downarrow, I L-1 \beta \downarrow, G S H \uparrow, \text { SOD } \uparrow, N F-\kappa B ~ p 65 \downarrow \text {, } \\
\text { TBARS } \downarrow, N r f 2 \uparrow, G C L c \uparrow\end{array}$ & Zong and Zhang, (2017) \\
\hline & LPS-induced RAW264.7 cells & $5,10 \mu \mathrm{g} / \mathrm{ml}$ & $\mathrm{NO} \downarrow$ & Kuo et al. (2019) \\
\hline & THP-1 cells & $0-30 \mu \mathrm{g} / \mathrm{ml}$ & PGE2 $\downarrow, \| L-6 \downarrow, T N F-\alpha \downarrow$ & Alkadi et al. (2021) \\
\hline \multirow[t]{18}{*}{$\begin{array}{l}\text { Anti- } \\
\text { microorganism }\end{array}$} & CVB3-infected Raji cells & $25-200 \mu \mathrm{M}$ & $\begin{array}{l}\text { Reduce coxsackievirus B3 replication, Inhibit } \\
\text { FAS activity }\end{array}$ & Wilsky et al. (2012) \\
\hline & $\begin{array}{l}\text { S. aureus, E. faecium, P. aeruginosa, S. } \\
\text { mutans, E. coli, E. coli-157 }\end{array}$ & $4,8,16,32 \mu \mathrm{g} / \mathrm{ml}$ & NADH depletion & Hwang et al. (2013) \\
\hline & $\begin{array}{l}\text { Mouse Gas Gangrene model, CPA-treated } \\
\text { Caco-2 cells, PFO-treated Caco-2 cells }\end{array}$ & $\begin{array}{l}50 \mathrm{mg} / \mathrm{kg}, 0-16 \mu \mathrm{g} / \mathrm{ml} \\
0-16 \mu \mathrm{g} / \mathrm{ml}\end{array}$ & $\begin{array}{l}\text { Block the hemolysis and cytotoxicity induced } \\
\text { by CPA and PFO, Survival rates } \uparrow \text {, Survival } \\
\text { time } \uparrow, \text { LDH release } \downarrow \text {, CPA-mediated } \\
\text { virulence } \downarrow \text {, PFO-mediated virulence } \downarrow\end{array}$ & Liu et al. (2020a) \\
\hline & SARS-CoV $3 \mathrm{CL}^{\text {pro }}$ inhibition assay & IC50: $8.3 \pm 1.2 \mu \mathrm{M}$ & Inhibit SARS-CoV 3CL ${ }^{\text {pro }}$ activity & Ryu et al. (2010) \\
\hline & C.albicans, S.cerevisiae, T.beigelii & MIC: $5 \mu \mathrm{g} / \mathrm{ml}, 5-10 \mu \mathrm{g} / \mathrm{ml}$ & $\begin{array}{l}\text { Induced the accumulation of intracellular } \\
\text { trehalose, Disrupt the dimorphic transition }\end{array}$ & Jung et al. (2006) \\
\hline & C.albicans & $5 \mu \mathrm{g} / \mathrm{ml}$ & Induce S-phase arrest & Jung et al. (2007) \\
\hline & C.albicans & $5 \mu \mathrm{M}$ & $\begin{array}{l}\text { Mitochondrial dysfunction, Induce apoptotic } \\
\text { cell death }\end{array}$ & Hwang et al. (2012) \\
\hline & Respiratory syncytial virus (RSV) & $\mathrm{IC}_{50}: 5.5 \mu \mathrm{g} / \mathrm{ml}$ & & Ma et al. (2001) \\
\hline & HIV-1 RT & $\mathrm{IC}_{50}: 119 \mu \mathrm{g} / \mathrm{ml}$ & & Lin et al. (1997) \\
\hline & DENV-NS5 RdRp & IC50: $1.3 \pm 0.1 \mu \mathrm{M}$ & Inhibition of DENV-NS5 RdRp & Coulerie et al. (2013) \\
\hline & CBV3-infected HEp-2 cells & $6.25-50 \mu \mathrm{g} / \mathrm{ml}$ & Virucidal activity $\uparrow$ & Yin et al. (2014) \\
\hline & $\begin{array}{l}\text { Pneumolysin (PLY)-mediated A549 cells, } \\
\text { S.pneumoniae strain D39- infected mice }\end{array}$ & 0-64 $\mu \mathrm{g} / \mathrm{ml}, 50 \mathrm{mg} / \mathrm{kg}$ & $\begin{array}{l}\text { Weaken hemolytic activity of PLY, Weaken } \\
\text { PLY-mediated A549 cell injury, Reduce the } \\
\text { virulence of PLY }\end{array}$ & Zhao et al. (2017b) \\
\hline & $\begin{array}{l}\text { S.suis-infected mice, S.suis serotype } 2 \\
\text { (SS2)-infected } \mathrm{J} 774 \text { cells }\end{array}$ & $100 \mathrm{mg} / \mathrm{kg}, 0-32 \mu \mathrm{g} / \mathrm{ml}$ & $\begin{array}{l}\text { TNF- } \alpha \downarrow \text {, IL-6 } \downarrow \text {, IL-1 } \beta \downarrow \text {, Lower mortality and } \\
\text { bacterial burden, p38 } \downarrow \text {, JNK1/2 } \downarrow \text {, NF- } \mathrm{B} \\
\text { p65 } \downarrow \text {, SLY pore-forming activity } \downarrow\end{array}$ & Shen et al. (2018) \\
\hline & S.aureus, E.coli & MIC: $62.5 \mu \mathrm{g} / \mathrm{ml}, 125 \mu \mathrm{g} / \mathrm{ml}$ & $\mathrm{K}+$ release $\uparrow$, ATP release $\uparrow$ & Bajpai et al. (2019) \\
\hline & HCV-infected Huh-7 cells & $1-100 \mu \mathrm{M}$ & $\begin{array}{l}\text { Inhibit HCV RNA replication, Circumvent } \\
\text { daclatasvir-induced RAVs (Resistance- } \\
\text { Associated Variants) }\end{array}$ & Lee et al. (2018c) \\
\hline & $\begin{array}{l}\text { HSV-1 infected Vero cells, HSV-1 infected } \\
\text { SK-N-SH cells }\end{array}$ & $2.5-50 \mu \mathrm{M}$ & $\begin{array}{l}\text { UL54 gene } \downarrow \text {, UL52 gene } \downarrow \text {, UL27 gene } \downarrow \text {, } \\
\text { ICP0 } \downarrow \text {, gD } \downarrow \text {, VP5 } \downarrow \text {, Inhibit ACV-resistant } \\
\text { strains, Reduce the nuclear transport }\end{array}$ & Li et al. (2019a) \\
\hline & M.aeruginosa & $32-512 \mu \mathrm{g} / \mathrm{ml}$ & $\begin{array}{l}\text { Ameliorate cell membranes, peptidoglycan } \\
\text { layers and cytoplasm, HCB control agent }\end{array}$ & Lee et al. (2020) \\
\hline & $\begin{array}{l}\text { L.amazonensis-infected peritoneal } \\
\text { macrophages, L.amazonensis-infected } \\
\text { mice }\end{array}$ & $0-11.4 \mu \mathrm{M}, 0.05 \mathrm{mg} / \mathrm{kg}$ & $\mathrm{NO} \downarrow$, iNOS $\downarrow, \mathrm{HO}-1 \downarrow$, Nrf2 $\downarrow$, Ferritin $\uparrow, \mathrm{ROS} \uparrow$ & Rizk et al. (2021) \\
\hline Pro-oxidation & HaCaT cells & $0-100 \mu \mathrm{M}$ & $\begin{array}{l}\mathrm{Nrf} 2 \uparrow, \mathrm{ARE} \uparrow, \mathrm{NQO}-1 \uparrow, \mathrm{ROS} \uparrow, \mathrm{p}-\mathrm{p} 38 \uparrow \\
\mathrm{p}-\mathrm{AKT} \uparrow, \mathrm{p}-\mathrm{ERK} 1 / 2 \uparrow\end{array}$ & Wahyudi et al. (2018) \\
\hline
\end{tabular}


TABLE 1 | (Continued) The mutiple biological activities of AMF.

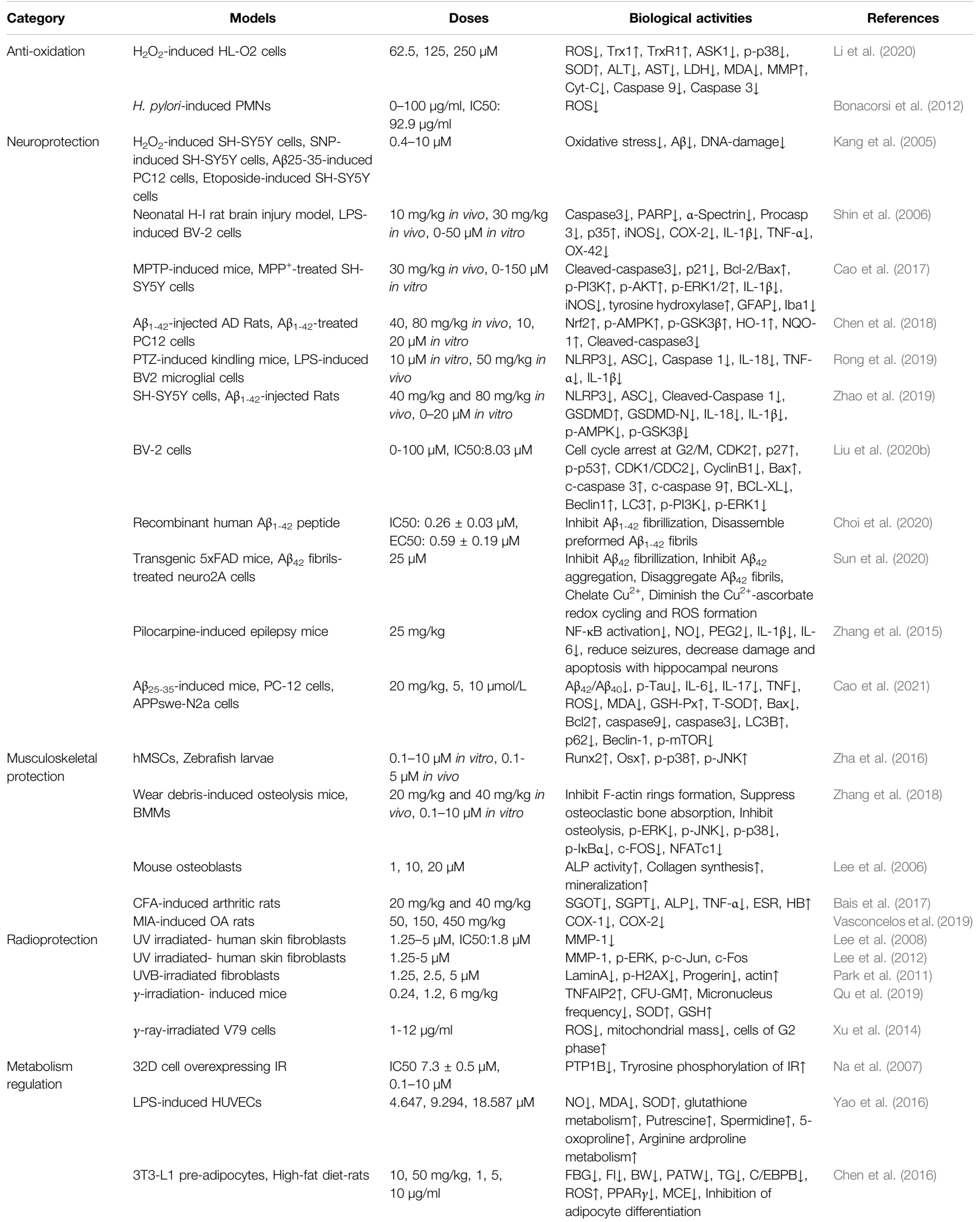


TABLE 1 | (Continued) The mutiple biological activities of AMF.

\begin{tabular}{|c|c|c|c|c|}
\hline Category & Models & Doses & Biological activities & References \\
\hline & High fructose and fat diet-induced MS rats & $100 \mathrm{mg} / \mathrm{kg}$ & $\begin{array}{l}\mathrm{PE} \downarrow \text {, Ach } \uparrow, \mathrm{NO} \uparrow, \mathrm{AT}-1 \mathrm{~A} \downarrow \text {, AT- } 2 \uparrow, \text { TBARS } \downarrow \text {, } \\
\mathrm{GSH} \uparrow, \mathrm{SOD} \uparrow \text {, Catalase } \uparrow, \mathrm{NADPH} \text { oxidase } \\
\text { activity } \downarrow\end{array}$ & Qin et al. (2018) \\
\hline & Diabetic mice & $20,40 \mathrm{mg} / \mathrm{kg}$ & 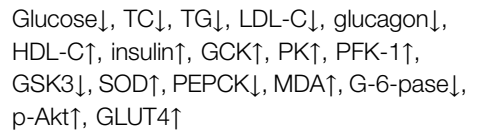 & Su et al. (2019) \\
\hline & KKAy mice & $0.2 \mathrm{~g} / \mathrm{kg}$ & 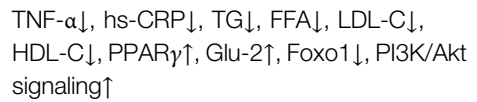 & Zhang et al. (2019) \\
\hline $\begin{array}{l}\text { Anxiolytic/ } \\
\text { antidepressant }\end{array}$ & Swiss albino mice & $6.25-50 \mathrm{mg} / \mathrm{kg}$ & $\begin{array}{l}\text { Bind to GABA receptor, Interact with 5-HT2 } \\
\text { receptor, Interact with a1-anda2- } \\
\text { adrenoceptors, Increase number of head- } \\
\text { dips }\end{array}$ & Ishola et al. (2012) \\
\hline
\end{tabular}

suis-infected cells by regulating the $\mathrm{p} 38, \mathrm{JNK} 1 / 2$ and NF- $\mathrm{BB}$ pathways (Shen et al., 2018). Moreover, Lee et al. (2020) find that AMF exhibits a powerful and selective killing effect on $M$. aeruginosa without harming other non-cyanobacteria. Bajpai et al. (2019) advocate that the antibacterial effects of AMF improves the nutritional quality of minced chicken meat and apple juice through its ability to alter cell membrane permeabilities of $S$. aureus and E. coli. In addition, Hwang et al. (2013) reveal that the antibacterial effect of AMF and its synergistic capacity with antibiotics are mainly from the induction of hydroxyl radicals and NADH depletion.

Leishmaniases are a complex of infectious diseases caused by protozoan parasites of the genus Leishmania transmitted by the bite of sandflies (Rizk et al., 2014; Rizk et al., 2021). AMF showed a leishmanicidal action on intracellular amastigote forms, independent of NO production (Rizk et al., 2014). In infected mice, the antileishmanial activity of amentoflavone has already been reported, the mechanisms involved in the parasite death of which increased ferritin expression, ROS production, and decreased NO and iNOS expression (Rizk et al., 2021).

\subsection{Anti-Oxidative/Pro-Oxidation Activity}

Oxidative stress has been manifested to be caused by the abnormal accumulation of reactive oxygen species (ROS) and reactive nitrogen species (RNS) and promotes aging and various diseases because of the oxidative damage of liposomes, nucleic acid and proteins (Pham-Huy et al., 2008; Schieber and Chandel, 2014).

Recently, Zong and Zhang (2017) report that AMF prevents acute lung injury due to Nrf2-GCLC-via oxidative stress in septic rats. Bajpai et al. (2019) also confirm that AMF exhibits an enormous antioxidant ability by inhibiting the production of hydroxyl radicals, superoxide, ABTS and DPPH in a variety of free radical scavenging models in vitro. The results of Li et al. (2020) suggest that the antioxidant protection of AMF blocks ASK1/p38 MAPK pathway and alleviates hepatotoxicity in $\mathrm{H}_{2} \mathrm{O}_{2}-$ induced HL-O2 cells by decreasing ROS generation. Bonacorsi et al. (2012) confirm that the AMF attenuates the effects of neutrophil generated ROS on gastric mucosa damage by inhibiting the oxidative burst of $\mathrm{H}$. pylori-induced PMNs in gastric ulcers.
However, Wahyudi et al. (2018) reveal that AMF exhibits the prooxidative activity through the Nrf2 activation induced by ROS-mediated the activation of p38-AKT pathway in HaCaT cells. In addition, AMF plays key role in the oxidant/ antioxidant balance by suppressing the production of inflammatory mediators (i.e., NO, COX-2) and proinflammatory cytokines (i.e., TNF- $\alpha$, IL- $1 \beta$ and IL-6), and the activation of NF- $\mathrm{KB}$ signaling pathways in vitro or/and in vivo (Ishola et al., 2013; Sakthivel and Guruvayoorappan, 2013).

\subsection{Neuroprotective Activity}

The neuroprotective effect of AMF is evident in its ability to against neurodegenerative diseases, including ischemic stroke (Shin et al., 2006), epilepsy (Zhang et al., 2015), Parkinson's disease (Cao et al., 2017) and Alzheimer's disease (Sasaki et al., 2015; Chen et al., 2018; Sabogal-Guaqueta et al., 2018).

Hypoxic-ischemic (H-I) brain injury occurs in infants and children, which leads to permanent neurological dysfunction including learning disabilities, seizure disorders, cognitive impairment and cerebral palsy (Ashwal and Pearce, 2001). Shin et al. (2006) reveal that AMF protects the brain against $\mathrm{H}$-I injury by blocking multiple molecular events which can lead to neuronal cell death. Mechanistically, AMF blocks apoptotic cell death via reducing the activation of caspase 3 and PARP after H-I injury.

Epilepsy is a common neurological disorder, which is characterized by recurrent and usually unprovoked epileptic seizures (Chang and Lowenstein, 2003). AMF effectively prevents the occurrence of seizures and diminishes the damage and apoptosis happening within hippocampal neurons through suppressing NF- $\kappa \mathrm{B}$ signaling pathway and the production of inflammatory mediators (i.e., NO, PGE2, IL-1 $\beta$ and IL-6) (Zhang et al., 2015).

Parkinson's disease (PD) is a progressive neurodegenerative disorder in the elder. PD is characterized by the degeneration of dopaminergic neurons and depletion of dopamine (DA), results in clinical symptoms of tremor, resting, bradykinesia and rigidity (de Lau and Breteler, 2006). Cao et al. (2017) disclose that AMF protects dopaminergic neurons against MPTP/MPP + -induced neurotoxicity through the activation of PI3K/Akt and ERK 
signaling pathways in dopaminergic neurons and the attenuation of neuroinflammation.

Alzheimer's disease (AD) is a common progressive neurodegenerative disorder of the central nervous system, which is characterized by the deposition of amyloid $\beta(A \beta)$ peptides as senile plaques and neurofibrillary tangles on neuronal cells (Baglietto-Vargas et al., 2016). Sasaki et al. (2015) find that AMF effectively protected PC-12 cells from A $\beta 42$-induced cytotoxic injury by inhibiting the activation of $\beta$-secretase and reducing oxidative damage. Sabogal-Guáqueta et al. (2018) demonstrate that the treatment with AMF reduces $\mathrm{A} \beta$ deposition, tau pathology, microgliosis, and astrogliosis via the reduction of $A \beta_{1-40}, A \beta_{1-42}$ and CTF $\beta$ in the brains of aged 3xTg-AD mice. Additionally, Chen et al. (2018) reveal that AMF exerts a protective effect against $A \beta_{1-42}$-induced deficits by modulating Nrf2 expression via AMPK signaling activation.

\subsection{Musculoskeletal Protection}

Musculoskeletal diseases (MSDs) are believed as one of the highest economic burdens to individuals and social-care systems (Woolf and Pfleger, 2003; Hoy et al., 2014). MSDs include osteoporosis (OP), rheumatoid arthritis (RA), osteoarthritis (OA), psoriatic arthritis (PsA), lower back pain (LBP) and gout (Lewis et al., 2019).

OP is known to occur due to a reduction in bone formation by osteoblasts and an increase in bone resorption by osteoclasts (Lee et al., 2006). Lee et al. (2006) report firstly in mouse osteoblasts that AMF significantly increases osteoblast differentiation by increasing alkaline phosphatase (ALP) activity and collagen synthesis, and results in mineralization. Zha et al. (2016) find that AMF significantly enhances cell proliferation, ALP activity and mineralization via increasing the levels of p-JNK and p-p38 in human mesenchymal stem cells (hMSCs). When the JNK and p38 MAPK pathways are inhibited by its inhibitors, the AMFinduced increases of ALP and mineralization are significantly lessened.

$\mathrm{OA}$ is a generally slow progression disease in which the inflammation plays a pivotal role in its pathogenesis (Wang et al., 2018). OA is characterized by pain, synovial inflammation, progressive destruction of articular cartilage, changes in the subchondral bone and peri-articular muscle (Robinson et al., 2016). Zhang et al. (2018) demonstrate the inhibition of AMF on osteoclast generation and wear debrisinduced osteolysis in vitro and in vivo. AMF suppresses osteoclastogenesis, F-actin ring formation and bone absorption in vitro, and prevents titanium wear debris-induced osteolysis in vivo via suppressing the MAPKs and NF- $\kappa \mathrm{B}$ pathways (Zhang et al., 2018). Also, Vasconcelos et al. (2019) suggest that AMF reduces the inflammatory process and improves OA through an interaction with cyclooxygenase- 2 .

RA is one of the most common inflammatory rheumatic diseases and is characterized by the development of a chronic inflammatory proliferation of the synovial linings of diarthrodial joints, which leads to aggressive cartilage destruction and progressive bony erosions (Lee and Weinblatt, 2001). Bais et al. (2017) reveal that AMF possesses potentially antiarthritic activity via improvement of joint activity, decreases the paw volume and reduces the serum inflammatory TNF-a level and other RA symptoms (i.e., joint stiffness, nodules, etc) in the adjuvant induced RA rats.

\subsection{Radioprotection}

Ultraviolet (UV) radiation causes the skin to age, which is commonly related to increased sagging, wrinkling and laxity (Jenkins, 2002). This skin aging can be attributed to extrinsic (known as photo-aging) and intrinsic aging (natural-aging) (Chung et al., 2001). Alterations in the extracellular matrix (ECM) of dermis layer are observed in extrinsic aged skin by repeated exposure to UV light (Kligman, 1989; Chung et al., 2001). UV irradiation induces the synthesis of MMPs in human skin in vivo, and MMPs-mediated collagen destruction accounts for the connective tissue damage that occurs in aging (Rittie and Fisher, 2002). Lee et al. (2008) find that AMF could inhibit the expression of MMP-1 in human dermal fibroblasts and this might be associated with the potent NO blocking effect of AMF. Moreover, the treatment of AMF blocks the up-regulation of UVB-induced MMP-1 via the suppression of the ERK pathway and the reduction of phosphorylated c-Jun and c-Fos protein expression (Lee et al., 2012). Park et al. (2011) suggest that AMF inhibits effectively UVB-induced nuclear aberration and DNA damage through the decrease of Lamin A or phospho-H2AX protein in normal human fibroblast.

Ionizing radiation is ubiquitous in modern life and can cause mitochondrial dysfunction by inducing mitochondrial membrane damage, the reduction of the cell's energy supply and the activation of the mitochondrial membrane potential (Xu et al., 2014). The protective effect of AMF against ionizing irradiation is investigated in irradiated v79 cells (Xu et al., 2014) and $\gamma$-irradiated mice (Qu et al., 2019). $\mathrm{Xu}$ et al reveal that the pretreatment with AMF $24 \mathrm{~h}$ prior to $8 \mathrm{~Gy}{ }^{60} \mathrm{Co} \gamma$-ray irradiation treatment increases the G2 phase, inhibits apoptosis, and decreases the concentration of ROS and mitochondrial mass in v79 cells (Xu et al., 2014). After mice were subjected to totalbody ${ }^{60} \mathrm{Co} \gamma$-irradiation, treatment with AMF markedly extends average survival time, alleviates impairment of the hematopoietic system and promotes its recovery (Qu et al., 2019). Furthermore, treatment with AMF attenuates radiation-induced oxidative stress through the increase of the SOD activity and GSH level (Qu et al., 2019). In addition, AMF significantly increases the expression of TNFAIP2 (Qu et al., 2019), which plays a role in $\mathrm{Wnt} / \beta$-catenin and NF- $\kappa \mathrm{B}$ signaling pathways (Chen et al., 2014).

\subsection{Metabolism Regulation}

Metabolic disorders such as type 2 diabetes mellitus (T2DM) and metabolic syndrome (MS) are prevalent worldwide and are associated with the disruption of glucose and lipid metabolism (Cho et al., 2018). The changes of general metabolic parameters involve in insulin level, fat mass, body weight and glucose tolerance (Qin et al., 2018). T2DM is characterized by increasing circulating glucose associated with abnormalities in carbohydrate, protein and fat metabolism caused by insufficiency of insulin secretion and insulin resistance (Alfa and Kim, 2016). The major characteristics of MS, as a collection of metabolic abnormalities, include cardiovascular dysfunction, 
hyperglycemia, hypertension, dyslipidaemia, insulin resistance, abdominal obesity and fatty liver (Torris et al., 2014).

It is reported that $\mathrm{AMF}$ could inhibit protein tyrosine phosphatase 1B (PTP1B) activity, therefore AMF has been proposed as a strategy for the treatment of T2D and obesity (Na et al., 2007). AMF treatment increases the phosphorylation of insulin receptor (IR) which is essential for the insulin signaling cascade in $32 \mathrm{D}$ cells with high-expressing IR. These results demonstrate that AMF enhances the activation of insulin signaling through inhibiting PTP1B activity ( $\mathrm{Na}$ et al., 2007). Su et al. (2019) reveal that AMF ameliorates the glucose and lipid metabolism disorder, the hepatic lipid accumulation of hepatic steatosis and repairing the histomorphologic change of pancreas. The abnormality of insulin signaling pathway plays an important role in the development of diabetes, so it is important to study the insulin signaling pathway (Brazil and Hemmings, 2001). PI3K/ Akt pathway is the key mediator in the metabolic function of insulin (Yao et al., 2014). Through activating the PI3K/Akt pathway, AMF exerts anti-diabetic effects by regulating the activities of key enzymes in glucose and lipid metabolism, increasing the insulin secretion and improving the insulin signal transduction (Su et al., 2019). Zhang et al. (2019) reveal that AMF plays a pivotal role in the treatment of T2D by reducing inflammatory responses, lowering blood lipids, activating the PPAR $\gamma$ and PI3K/Akt signaling pathway in the KKAy insulinresistant diabetes mice. Qin et al. (2018) show that AMF protects against cardiovascular ardiovascular and liver dysfunction by involving the modulation of Ang II signaling and oxidative stress through the regulation of $\mathrm{NADPH}$ oxidase in high fructose and fat diet (HFFD)-induced MS rats. AMF protects against cardiovascular dysfunction by increasing fractional shortening and decreasing systolic blood pressure, estimated LV mass, LVIDd, relative wall thickness, LVPWd, cardiac stiffness and LV wet weight (Qin et al., 2018). AMF also protects against liver dysfunction through increasing GSH, SOD level and CAT activities, and decreasing NADPH oxidase activities (Qin et al., 2018). In addition, Chen et al. (2016) demonstrate that AMF can protect against high fat dietinduced metabolic dysfunction and inhibit 3T3-L1 adipocyte differentiation. Mechanically, AMF not only promotes ROS generation, but also decreased CCAAT/enhancer-binding protein $(\mathrm{C} / \mathrm{EBP}) \beta$ expression, and results in the inhibition of mitotic clonal expansion (MCE) (Chen et al., 2016). In summary, $\mathrm{AMF}$ inhibits $\mathrm{C} / \mathrm{EBPa}$ and $\mathrm{PPAR} \gamma$ expression, suppresses molecular pathways that responsible for the formation of lipid droplets, and leads to the inhibition of early and terminal differentiation (Chen et al., 2016).

\subsection{Anxiolytic/Antidepressant}

The anxiolytic effect is studied using the elevated plus maze (EPM), hole-board and light-dark tests (Durcan and Lister, 1989). The tail suspension tests (TST) and forced swimming tests (FST) models are used to evaluate the antidepressant effect (Steru et al., 1985). Ishola et al obtains evidences for the anxiolytic/ antidepressant effect of AMF in mice, and the results suggest that AMF attenuates anxiety by increasing the time spent on the open arms in the EPM, the number of head-dips in the hole- board test and the exploration of the light chamber in the lightdark test (Ishola et al., 2012). In addition, AMF produces its anxiolytic effect through involving GABAergic (ionotropic GABA receptor) system, while the antidepressant effect through interacting with serotonergic (5-HT2 receptors) and noradrenergic (a1-and a2-adrenoceptors) systems (Ishola et al., 2012).

\subsection{Anti-cancer Effect}

Increasing evidences demonstrate that AMF controls cell proliferation, apoptosis, invasion, metastasis, autophagy, transcription and drug-resistance in various types of cancers, such as lung cancer (Banerjee et al., 2002a; Banerjee et al., 2002b; Jung et al., 2017; Hu et al., 2018; Park and Kim, 2019; Shen et al., 2019; Kim et al., 2020; Chen et al., 2021), cervical cancer (Lee et al., 2011), ovarian cancer (Liu et al., 2017a; Zhang et al., 2020), bladder cancer (Chiang et al., 2019), osteosarcoma (Pan et al., 2017; Lee et al., 2019), melanoma (Guruvayoorappan and Kuttan, 2007; 2008b; a; Siveen and Kuttan, 2011), breast cancer (Lee et al., 2009; Pei et al., 2012; Lee et al., 2013; Chen et al., 2015; Aliyev et al., 2021), liver cancer (Zheng et al., 2016; Chen et al., 2017a; Lee et al., 2018a; Lee et al., 2018b; Tsai et al., 2018), brain cancer (Yen et al., 2018; Zhaohui et al., 2018; Hsu et al., 2019; Chen et al., 2020c), and oral squamous cell carcinoma (Chen et al., 2020b) via regulating kinds of signaling pathways (Figure 2). These studies provide a lot of evidences that AMF is a potential effective multitargeting drug for the prevention and treatment of a variety of cancers. AMF has a series of molecular targets and the underlying mechanisms are mainly through regulating the expression of different genes involved in cancer cell growth, cell cycle, apoptosis, autophagy, metastasis, angiogenesis, and epigenetic modification, etc (Table 2 and Figure 3).

\subsubsection{Cell Cycle Arrest}

AMF has been confirmed to induce cell cycle arrest in multiple cancer cells, such as, lung (Shen et al., 2019), cervical (Lee et al., 2011), melanoma (Siveen and Kuttan, 2011), and ovarian cancer cells (Liu et al., 2017a). In non-small cell lung cancer cells, AMF treatment significantly increases the cell population at G1/G0 phase by decreasing the expression of cyclin D1, CDK4 and CDK6 in both H358 and H1299 cells (Shen et al., 2019). Similarly, AMF treatment induces a significant cell cycle arrest at G1/G0 phase via elevating the levels of p21 and p27 and decreasing the level of CDK2 in SKOV3 and OVCAR-3 cells (Liu et al., 2017a). Treatment of B16F-10 cells with AMF could also increase the percentage of cells in the sub-G0/G1 phase by downregulating cyclin D1 and Bid proteins (Siveen and Kuttan, 2011). Additionally, the treatment of SiHa and CaSki cells with AMF induces cell cycle arrest at the sub-G1 phase through the down-regulation of $p-p R b$ and G1/S cyclins and the up-regulation of p21 and p27 via a p53-dependent pathway (Lee et al., 2011). Besides the effect of AMF on G1phase cell cycle arrest, AMF treatment can inhibit cell proliferation, interrupt the balance of microtubule dynamics and arrest cells at the G2 phase via increasing p21 expression and decreasing CDK1/2 expression in ovarian cancer SKOV3 cells (Zhang et al., 2020). 


\subsubsection{Apoptosis Induction}

Apoptosis is the process of programmed cell death. The induction of cell apoptosis is an important strategy for anti-cancer activity (Taylor et al., 2008). Caspase activation plays a crucial role in apoptosis-mediated cancer cell death (Fischer et al., 2007). Caspase-3 mediates the proteolytic cleavage of poly adenosine diphosphate-ribose polymerase (PARP) and plays an important role in condensation and degradation of chromatin in cells. A large number of reports reveal the effect of AMF in the induction of apoptosis through either intrinsic (mitochondria-mediated) and/or extrinsic pathway in different cancer cells. In the mitochondria-mediated pathway, AMF treatment decreases the expression of anti-apoptotic factor $\mathrm{Bcl}-2$ and increases the expression of pro-apoptotic factor Bax, thereby cytochrome- $\mathrm{C}$ is released to cytosol accompanying the activation of caspases-3/9 and PARP in cervical cancer SiHa and CaSki cells (Lee et al., 2011). Additionally, AMF induces MCF-7 cells to undergo apoptosis via the ROS- and $\mathrm{Ca}^{+2}$-involved mitochondriadependent pathway (Pei et al., 2012). In B16F-10 melanoma cells, AMF treatment induced apoptosis through p53-dependent intrinsic apoptotic pathway by increasing Bax and caspase- 9 protein levels (Siveen and Kuttan, 2011). In addition to the intrinsic pathway, there are some reports on the apoptotic effect of AMF through the extrinsic pathways. AMF inhibits multiple anti-apoptotic proteins, such as XIAP, C-FLIP and Mcl1 (Igney and Krammer, 2002). In SK-Hep1R cells, AMF not only promotes sorafenib-induced apoptosis through intrinsic pathway via enhancing cleaved-caspase-8/3 and cyto-c release, but also promotes sorafenib-induced extrinsic apoptosis pathway through inhibiting the expression of XIAP, C-FLIP and Mcl-1 proteins (Chen et al., 2017a). In bladder cancer, AMF induces FAS/FASLdependent extrinsic apoptosis through increasing pro-apoptotic protein levels of FAS and FASL (Chiang et al., 2019). Moreover, AMF also induces the apoptotic pathway by increasing the expressions of PTEN (Lee et al., 2011), phosphorylated JNK (Lee et al., 2013) and decreasing the expressions of phosphorylated AKT (Tsai et al., 2018) and ERK (Lee et al., 2019).

\subsubsection{Autophagy Induction}

Autophagy is a cell degradation pathway used to remove damaged or redundant proteins and organelles, and is also associated with tumorigenesis (Mathew et al., 2007). Mammalian target of rapamycin (mTOR) is one part of mTOR complex 1 (mTORC1) and a major regulator of cell growth and autophagy (Jewell et al., 2013). ATG, Beclin 1 and LC3 are the proteins involved in multiple processes of autophagosome formation and are essential for autophagy (Park and Kim, 2019; Wang and Wang, 2019). Previous studies have confirmed that AMF can induce autophagic cell death in several cancer cells, such as glioma (Chen et al., 2020c) and lung (Park and Kim, 2019). AMF increases the autophagic flux of glioma U251 and U373 cells via up-regulating the autophagy-relevant proteins, such as Beclin1, LC3B, ATG5, ATG7 (Chen et al., 2020c) and the phosphorylation of AMPK or suppressing the phosphorylation of mTOR and p70S6K (Chen et al., 2020c). Moreover, AMF promotes ferroptosis in autophagy-dependent manner. The knockdowns of ATG7 and autophagy inhibitor Baf A1 are able to abrogate AMF-inducing ferroptosis and autophagic cell death in glioma cells (Chen et al., 2020c).

\subsubsection{Signaling Pathways Regulation}

Previous studies have confirmed that AMF exerts an inhibitory effect on multiple signaling pathways, such as NF- $\mathrm{BB}, \mathrm{PI} 3 \mathrm{~K} / \mathrm{AKT}$, ERK, JNK and AMPK/mTOR pathway. As a heterodimeric transcription factor, $\mathrm{NF}-\mathrm{\kappa B}$ is composed of $\mathrm{p} 50$ and $\mathrm{p} 65$ subunits, mediates tumor invasion and metastasis through regulating the expressions of metastasis-associated proteins such as XIAP, MMP-2, MMP-9, cyclinD1, and VEGF (Rasmi et al., 2020). In vitro studies, AMF suppresses cell viability, invasion and migration of different types of cancers, including glioblastoma (Hsu et al., 2019) and HCC (Lee et al., 2018b) through inhibiting NF- $\kappa \mathrm{B}$ activation and NF- $\mathrm{BB}$-mediated downstream gene expression. Similarly, AMF reduces the invasion ability of NSCLC cells through blocking NF- $\kappa \mathrm{B}$ signaling pathway and NF- $\mathrm{B}$ p65 nuclear translocation (Chen et al., 2021). Furthermore, AMF inhibits osteosarcoma and HCC progression in vivo by suppressing ERK/NF- $\kappa \mathrm{B}$ activation (Lee et al., 2018a; Lee et al., 2019). AMF also enhances insulin resistance of HepG2 cells through the PI3K-Akt signaling pathway (Zheng et al., 2016). In addition, AMF induces caspase-dependent apoptosis, exerts FASN-inhibitory activity and decreases cell proliferation via suppressing HER2 activation and modulating the expressions of Akt, mTOR and p-JNK in SKBR3 cells (Lee et al., 2009; Lee et al., 2013). AMF represses ovarian cancer and the expression of Skp2 through ROS/AMPK/mTOR signaling pathway in xenograft mouse model (Liu et al., 2017a). AMF inhibits cell growth and induces ferroptosisin in glioma U251 and U373 cells through modulating iron homeostasis via repressing ferritin heavy chain (FTH). AMF suppresses FTH expression through the induction of autophagy via AMPK/mTOR/p70S6K signaling pathway (Chen et al., 2020c).

\subsubsection{Metastasis and Angiogenesis}

Epithelial mesenchymal transition (EMT) is essential for driving plasticity during development, and is believed to play an important role in the metastasis of many cancers (Jou and Diehl, 2010; De Craene and Berx, 2013). Several proteins and transcription factors, such as Ecadherin, Snail and Twist, have been proved to drive EMT process (Kalluri and Weinberg, 2009). AMF inhibits EMT via the inhibition of Snaill/Twist signaling axis in both A549 and HT29 cells (Kim et al., 2020). MMP-2 and MMP-9 promote the degradation of basement membrane and lead to tumor cell invasion and metastasis (Liu et al., 2017b). AMF prevents bladder cancer invasion and migration by reversing EMT via $\mathrm{NF}-\kappa \mathrm{B}$ inactivation and by reducing the expression of MMP-2, MMP-9 and uPA (Chiang et al., 2019).

Angiogenesis is critical for multiple physiological and pathological processes (Guruvayoorappan and Kuttan, 2008c). Angiogenesis is a mandatory factor for tumor metastasis. The inhibition of angiogenesis is a strategy for tumor treatment (Liu et al., 2017b). In vitro studies, AMF may induce anti-angiogenesis of MCF cells via inhibiting the expression and secretion of VEGF 


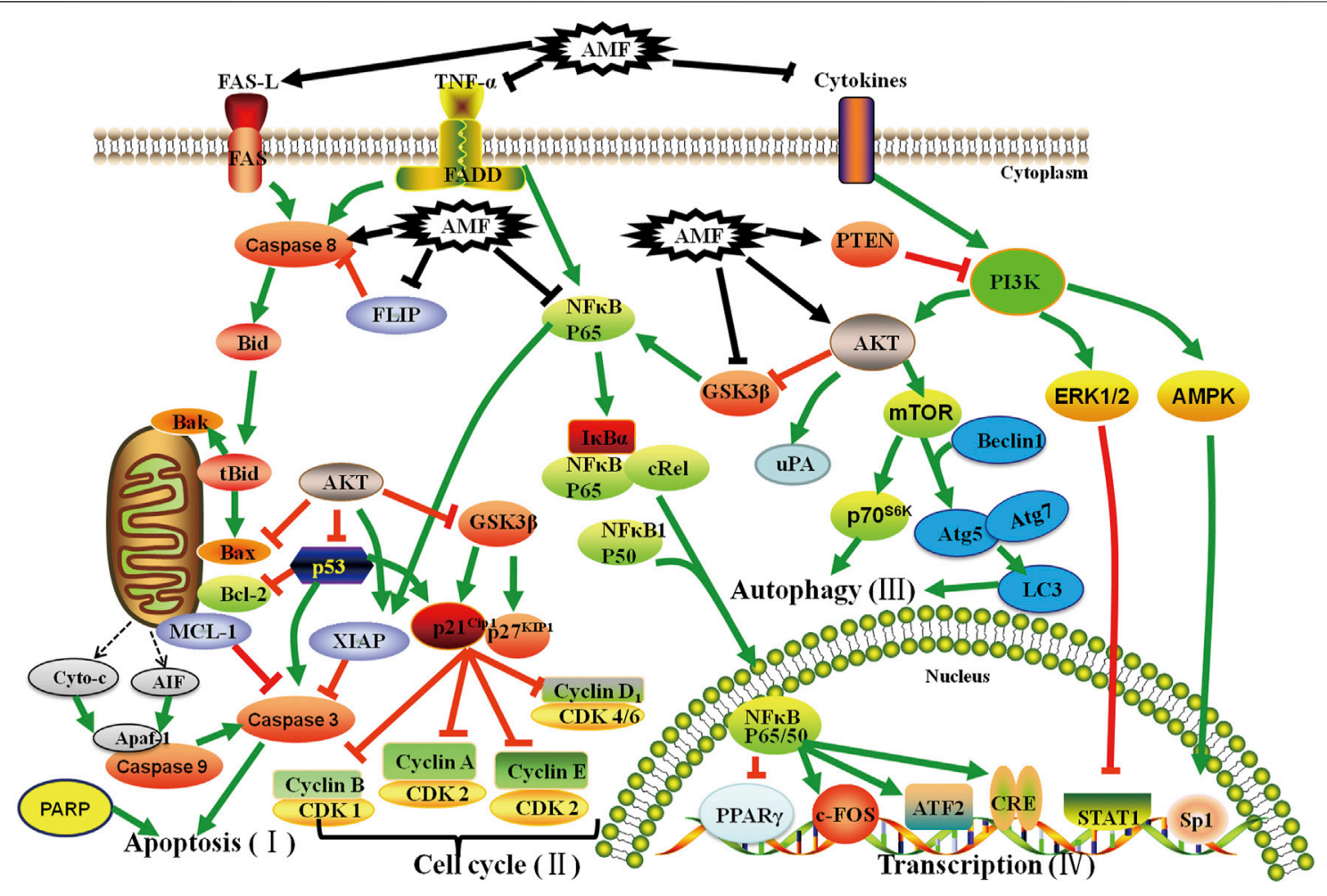

FIGURE 2 | Effect of AMF on Apoptosis (I), Cell cycle (II), Autophagy (III) and Transcription (IV) of various cancers through different molecular signaling pathways. AMF: Amentoflavone; T: Inhibition; $\uparrow:$ Activation; T: Inhibition by AMF; $\uparrow$ : Activation by AMF.

through NF- $\kappa B$ inactivation (Chen et al., 2015). AMF also attenuates tumor invasion and angiogenesis in osteosarcoma U2OS cells (Pan et al., 2017), melanoma B16F10 cells (Guruvayoorappan and Kuttan, 2008b), and NSCLC cells (Chen et al., 2021). In vivo study, AMF treatment reduces B16F-10 melanoma cells-induced lung metastasis in transplanting C57BL/6 mice (Guruvayoorappan and Kuttan, 2007; 2008a). It is reported that AMF can inhibit VEGFAinduced chorioallantoic membrane neovascularization in xenograft colon carcinoma mice. AMF inhibits endothelial cell migration and VEGFA or PIGF-1-induced capillary-like tube formation, and prevents the interaction between VEGFs and VEGF receptor 1/2 (VEGFR-1/-2) by binding with proangiogenic VEGFs (Tarallo et al., 2011).

In addition to the anti-cancer effect of AMF by inhibiting angiogenesis, AMF also plays an important role in some nonneoplastic diseases. In hypertrophic scar fibroblasts, AMF inhibits angiogenesis of endothelial cells by inhibiting the viability, migration and tube formation (Zhang et al., 2014). In vasodilation, AMF relaxes vascular smooth muscle via the activation of endothelium-dependent NO-cGMP signaling pathway which may be involved in the functions of $\mathrm{K}^{+}$and $\mathrm{Ca}^{2+}$ channels (Kang et al., 2004). It is reported that AMF may exert a vasodilating effect through a NO-independent, cGMPPDE5-dependent mechanism in the smooth muscle cells of the arterial wall (Dell'Agli et al., 2006).

\subsubsection{Epigenetic Modification}

Epigenetic modification of nucleic acids occurs broadly both in DNA and in RNA and is involved in growth, heredity and diseases (Chen et al., 2017b). Previous studies reveal that AMF exerts anticancer effects via regulating the expression of epigenetic modification genes in cancer cells. AMF attributes to apoptosis and glycolysis inhibition by up-regulating miR-124$3 p$ through repressing DNMT1. Followed that, AMF suppresses DNMT1 expression via the activation of ROS/AMPK and Sp1 signaling pathways (Zhaohui et al., 2018). Moreover, in ovarian cancer cells AMF enhances the occurrence of DNA damage by increasing the expression levels of $\gamma$-H2AX and Rad51 (Zhang et al., 2020).

\subsubsection{Drug Resistance}

Drug resistance remains the main limiting factor for the cure of cancer patients (Vasan et al., 2019). Some traditional Chinese medicines are becoming new strategies for tumor treatment by combining chemotherapeutic drugs. AMF can synergistically increase the cytotoxic effects of carboplatin in A549 cells and may be a potential chemosensitizer to carboplatin for NSCLC through PARP-1 in vitro and in vivo (Hu et al., 2018). AMF not only significantly enhances cisplatin-induced cytotoxicity via NF$\kappa \mathrm{B}$ inactivation, but also significantly increases the cisplatinmediated inhibition of cell proliferation, invasion and migration of oral squamous carcinoma SAS cells (Chen et al., 
TABLE 2 | AMF and the underlying mechanisms against different cancers.

\begin{tabular}{|c|c|c|c|c|}
\hline Cancer & Models & Biological activities & Molecular mechanisms & References \\
\hline \multirow[t]{8}{*}{ Lung cancer } & A549 cells & PGE2 biosynthesis suppression & COX-2/iNOS $\downarrow$ & Banerjee et al. (2002b) \\
\hline & $\begin{array}{l}\text { TNF- } \alpha \text {-activated A549 } \\
\text { cells }\end{array}$ & inhibition of NF-кB/DNA binding activity & $\mathrm{COX}-2 \downarrow, \mid \kappa \mathrm{B} a \downarrow, \mathrm{PPAR}-\gamma \uparrow$ & Banerjee et al. (2002a) \\
\hline & A549 cells & $\begin{array}{l}\text { a potential PARP-1 inhibitor, Cytotoxic of } \\
\text { carboplatin } \uparrow\end{array}$ & PARP-1 $\downarrow$ & Hu et al. (2018) \\
\hline & A549 and WI-38 cells & induction of autophagy & 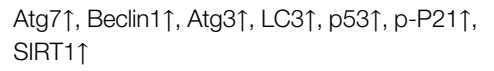 & Park and Kim, (2019) \\
\hline & H1299 and H358 cells & anti-growth and pro-apoptotic activities & $\begin{array}{l}\text { CyclinD1 } \downarrow \text {, CDK4 } 4 \text {, CDK6 } \downarrow \text {, Caspase } 3 \uparrow, \\
\text { Bax } \uparrow, \text { Bcl2 } \downarrow, \text { CIP2A } \downarrow\end{array}$ & Shen et al. (2019) \\
\hline & $\begin{array}{l}\text { TGF- } \beta \text {-induced A549 } \\
\text { cells }\end{array}$ & anti-metastatic activity & E-cadherin $\uparrow$, Snail $\downarrow$, Twist $\downarrow$ & Kim et al. (2020) \\
\hline & CL-1-5-F4 cells & $\begin{array}{l}\text { Cell-cycle arrest, apoptosis induction, NF-кB } \\
\text { signaling inhibition, growth and invasion } \\
\text { inhibition }\end{array}$ & 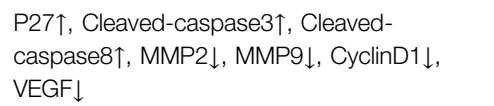 & Chen et al. (2021) \\
\hline & $\begin{array}{l}\text { A549 cells, } \mathrm{NCl}-\mathrm{H} 460 \\
\text { cells, A549 tumor } \\
\text { xenograft mice }\end{array}$ & Inhibit cell proliferation & AKR1B10 & Jung et al. (2017) \\
\hline Cervical cancer & SiHa and CaSki cells & $\begin{array}{l}\text { apoptosis induction, cell cycle arrest at sub- } \\
\text { G1 phase }\end{array}$ & 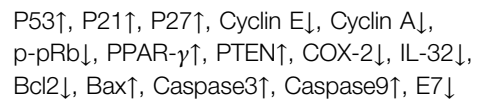 & Lee et al. (2011) \\
\hline \multirow[t]{2}{*}{ Ovarian cancer } & $\begin{array}{l}\text { SKOV3 and OVCAR-3 } \\
\text { cells }\end{array}$ & cell apoptosis and cell cycle arrest induction & $\begin{array}{l}\text { Skp2 } \downarrow, \mathrm{P} 21 \uparrow, \mathrm{P} 27 \uparrow, \mathrm{CDK} 2 \downarrow, \mathrm{ROS} / \mathrm{AMPK} \\
\text { mTOR signaling } \uparrow\end{array}$ & Liu et al. (2017a) \\
\hline & SKOV3 cells & cell cycle G2/M arrest, DNA damage induction & $\mathrm{P} 21 \uparrow, \mathrm{CDK} 1 / 2 \downarrow, \gamma-\mathrm{H} 2 \mathrm{AX} \uparrow, \operatorname{Rad} 51 \uparrow$ & Zhang et al. (2020) \\
\hline Bladder cancer & TSGH8301 & $\begin{array}{l}\text { apoptosis induction, inhibition of anti- } \\
\text { apoptotic and metastasis-associated proteins }\end{array}$ & $\begin{array}{l}\mathrm{FAS} \uparrow, \mathrm{FASL} \uparrow, \mathrm{Bax} \uparrow, \mathrm{MCL}-1 \downarrow \text {, C-FLIP } \downarrow \\
\text { MMP2 } \downarrow, \text { MMP9 } \downarrow, \text { VEGF } \downarrow, \text { UPA } \downarrow \text {, CyclinD1 } \downarrow\end{array}$ & Chiang et al. (2019) \\
\hline \multirow[t]{2}{*}{ Osteosarcoma } & U2OS cells & $\begin{array}{l}\text { inhibition of metastasis-associated proteins, } \\
\text { cell migration, and cell invasion }\end{array}$ & $\begin{array}{l}\text { p-ERK } \downarrow, N F-\kappa B \text { activity } \downarrow, M M P 2 \downarrow, \text { MMP } 9 \downarrow \text {, } \\
\text { VEGF } \downarrow, \text { uPA } \downarrow\end{array}$ & Pan et al. (2017) \\
\hline & U2OS cells & Tumor progression inhibition & $\begin{array}{l}\text { p-ERK } \downarrow, N F-\kappa B ~ p-P 65 \downarrow, X I A P \downarrow, M M P 9 \downarrow \\
\text { VEGF } \downarrow \text {, CyclinD1 } \downarrow\end{array}$ & Lee et al. (2019) \\
\hline \multirow[t]{4}{*}{ Melanoma } & $\begin{array}{l}\text { B16F-10-injected- } \\
\text { C57Bl/6 mice }\end{array}$ & Inhibition of pulmonary metastasis & $\begin{array}{l}\text { TIMP1 } \uparrow, T I M P 2 \uparrow, ~ I L-6 \downarrow, I L-1 \beta \downarrow, G M-C S F \downarrow \\
\text { TNF- } \alpha \downarrow, N F-\kappa B \downarrow \text {, c-FOS } \downarrow, \text { ATF } 2 \downarrow, \text { CRE-B } \downarrow\end{array}$ & $\begin{array}{l}\text { Guruvayoorappan and } \\
\text { Kuttan, (2007) }\end{array}$ \\
\hline & $\begin{array}{l}\text { B16F-10-injected- } \\
\text { C57Bl/6 mice }\end{array}$ & $\begin{array}{l}\text { attenuation of tumor invasion, proliferation and } \\
\text { angiogenesis }\end{array}$ & 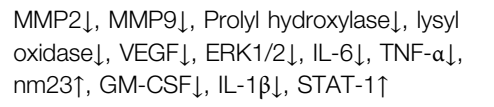 & $\begin{array}{l}\text { Guruvayoorappan and } \\
\text { Kuttan, (2008a) }\end{array}$ \\
\hline & B16F-10 cells & apoptosis induction & $\begin{array}{l}\mathrm{NO} \downarrow, I L-6 \downarrow, \mathrm{TNF}-\alpha \downarrow, \mathrm{Bcl} 2 \downarrow, \mathrm{GM}-\mathrm{CSF} \downarrow, \mathrm{IL}- \\
1 \beta \downarrow, \mathrm{P} 53 \uparrow, \text { Caspase3 }\end{array}$ & $\begin{array}{l}\text { Guruvayoorappan and } \\
\text { Kuttan, (2008b) }\end{array}$ \\
\hline & B16F-10 cells & apoptosis induction, cell G0/G1 phase arrest & 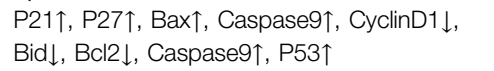 & $\begin{array}{l}\text { Siveen and Kuttan, } \\
\text { (2011) }\end{array}$ \\
\hline \multirow[t]{5}{*}{ Breast cancer } & SKBR3 cells & $\begin{array}{l}\text { blockade of fatty acid synthesis, apoptosis } \\
\text { induction, anti-proliferation }\end{array}$ & $\begin{array}{l}\text { Cleaved-caspase } 3 \uparrow, \mathrm{PARP} \uparrow, \mathrm{FASN} \text { activity } \downarrow \text {, } \\
\text { DNA fragmentation } \uparrow\end{array}$ & Lee et al. (2009) \\
\hline & MCF-7 cells & apoptosis induction, cell cycle arrest & $\begin{array}{l}\mathrm{ROS} \downarrow \text {, Bcl } 2 \downarrow \text {, Bax } \uparrow, \mathrm{AIF} \uparrow, \mathrm{P} 53 \uparrow, \mathrm{Bid} \downarrow \\
\text { Caspase } 3 \uparrow\end{array}$ & Pei et al. (2012) \\
\hline & SKBR3 cells & $\begin{array}{l}\text { fatty acid synthase inhibition, enhance chemo- } \\
\text { preventive or chemotherapeutic activity }\end{array}$ & $\begin{array}{l}\text { FASN } \downarrow, \text { HER } 2 \downarrow, \text { PEA3 } \uparrow, P A R P \uparrow, \text { SREBP- } 1 \downarrow \text {, } \\
\text { Caspase } \uparrow \uparrow, p-A K T \downarrow, p-J N K \downarrow, p-m T O R \downarrow\end{array}$ & Lee et al. (2013) \\
\hline & MCF-7 cells & $\begin{array}{l}\text { anti-angiogenesis and anti-metastasis } \\
\text { induction }\end{array}$ & VEGF $\downarrow, M M P 2 \downarrow$, MMP9 $\downarrow, N F-\kappa B ~ p-P 65 \downarrow$ & Chen et al. (2015) \\
\hline & $\begin{array}{l}\text { MCF-7 cells, MDA-MB- } \\
231 \text { cells, MCF-10A } \\
\text { cells }\end{array}$ & $\begin{array}{l}\text { Aromatase inhibition, cytotoxic, bind to the } \\
\text { active site of hCYP19A1 }\end{array}$ & hCYP19A1 $\downarrow$ & Aliyev et al. (2021) \\
\hline \multirow[t]{5}{*}{$\begin{array}{l}\text { Hepatocellular } \\
\text { carcinoma }\end{array}$} & HepG2 cells & Improvement of insulin resistance & $\begin{array}{l}\mathrm{PI} 3 \mathrm{~K} \uparrow, \mathrm{AKT} \uparrow, \mathrm{p}-\mathrm{AKT} \uparrow, \mathrm{GCK} \uparrow, \mathrm{PFK}-1 \uparrow, \mathrm{TNF}- \\
a \downarrow, \mathrm{PK} \uparrow, \mathrm{GSK}-3 \downarrow, \mathrm{PEPCK} \downarrow, \mathrm{L}-6 \downarrow, \mathrm{G}-6- \\
\text { Pase } \downarrow, \mathrm{IL}-8 \downarrow, \mathrm{CRP} \downarrow\end{array}$ & Zheng et al. (2016) \\
\hline & $\begin{array}{l}\text { Sorafenib-resistant Sk- } \\
\text { Hep1 cells }\end{array}$ & $\begin{array}{l}\text { enhance sorafenib-induced cytotoxicity, } \\
\text { trigger sorafenib-induced apoptosis }\end{array}$ & $\begin{array}{l}\text { DNA fragmentation } \uparrow, \mathrm{XIAP} \downarrow, \mathrm{MCL}-1 \downarrow \text {, } \\
\text { C-FLIP } \downarrow \text {, Cleaved-caspase } 3 \uparrow \text {, Cleaved- } \\
\text { caspase8 } \uparrow, \text { Cyto-c } \uparrow\end{array}$ & Chen et al. (2017a) \\
\hline & $\begin{array}{l}\text { SK-Hep1 tumor- } \\
\text { bearing mice }\end{array}$ & $\begin{array}{l}\text { apoptosis induction, enhance sorafenib- } \\
\text { inhibited tumor growth }\end{array}$ & 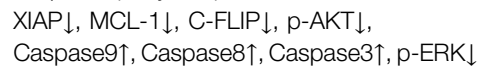 & Tsai et al. (2018) \\
\hline & SK-Hep1 cells & $\begin{array}{l}\text { Reduction of cell viability, NF-кB activation, } \\
\text { and cell invasion }\end{array}$ & p-ERK $\downarrow$, MMP9 $\downarrow$, XIAP $\downarrow$, VEGF $\downarrow$, CyclinD1 $\downarrow$ & Lee et al. (2018b) \\
\hline & $\begin{array}{l}\text { SK-Hep1 tumor- } \\
\text { bearing mice }\end{array}$ & $\begin{array}{l}\text { Inhibition of tumor growth and ERK/NF-кB } \\
\text { activation }\end{array}$ & $\begin{array}{l}\mathrm{p}-\mathrm{ERK} \downarrow, \mathrm{MMP} 9 \downarrow, \mathrm{XIAP} \downarrow, \mathrm{MCL}-1 \downarrow, \mathrm{C}-\mathrm{FLIP} \downarrow \\
\text { VEGF} \downarrow, \text { CyclinD1 } 1, \mathrm{NF}-\kappa \mathrm{B} \text { p-P65 } \downarrow\end{array}$ & Lee et al. (2018a) \\
\hline Brain cancer & U87MG Cells & $\begin{array}{l}\text { apoptosis induction, inhibition of NF-kB- } \\
\text { modulated anti-apoptotic signaling }\end{array}$ & NF-kB activity $\downarrow, M C L-1 \downarrow, \mathrm{C}-\mathrm{FLIP} \downarrow$ & Yen et al. (2018) \\
\hline
\end{tabular}


TABLE 2 | (Continued) AMF and the underlying mechanisms against different cancers.

\begin{tabular}{|c|c|c|c|c|}
\hline Cancer & Models & Biological activities & Molecular mechanisms & References \\
\hline & $\begin{array}{l}\text { U87, LV229, U251, } \\
\text { LN18 and U373 cells }\end{array}$ & $\begin{array}{l}\text { proliferation inhibition, apoptosis induction, } \\
\text { glycolysis suppression }\end{array}$ & & \\
\hline & GBM8401 & $\begin{array}{l}\text { blockage of ERK/NF- } \mathrm{kB} \text { signaling, inhibition of } \\
\text { tumor growth }\end{array}$ & $\begin{array}{l}\text { ERK/NF-kB activity } \downarrow, M M P 2 \downarrow, M M P 9 \downarrow \\
\text { XIAP } \downarrow \text {, CyclinD1 } \downarrow, \text { VEGF } \downarrow\end{array}$ & Hsu et al. (2019) \\
\hline & U251 and U373 cells & $\begin{array}{l}\text { cell proliferation suppression, cell death } \\
\text { induction, triggering autophagy-dependent } \\
\text { ferroptosis }\end{array}$ & $\begin{array}{l}\text { MDA } \uparrow, \text { GSH } \downarrow \text {, LC3B } \uparrow, \text { Beclin1 } 1, \text { ATG5 } \uparrow, \\
\text { ATG7 } \uparrow, F H \downarrow \text {, lipid OS } \uparrow, \text { CyclinD1, CyclinB1 } \downarrow \text {, } \\
\text { CDK2 } \downarrow, \text { CDK4 } \downarrow, \text { p-AMPK } \downarrow, \text { p-mTOR } \downarrow, \\
\text { p-P70 } \downarrow\end{array}$ & Chen et al. (2020c) \\
\hline $\begin{array}{l}\text { Oral Squamous } \\
\text { Cell Carcinoma }\end{array}$ & SAS cells & $\begin{array}{l}\text { Increasing cisplatin-induced cytotoxicity, } \\
\text { enhancing cisplatin-induced apoptosis, } \\
\text { augmenting cisplatin-suppressed invasion and } \\
\text { migration ability }\end{array}$ & 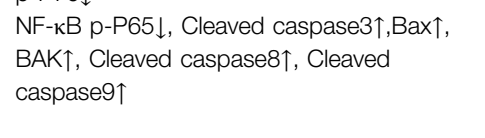 & Chen et al. (2020b) \\
\hline
\end{tabular}

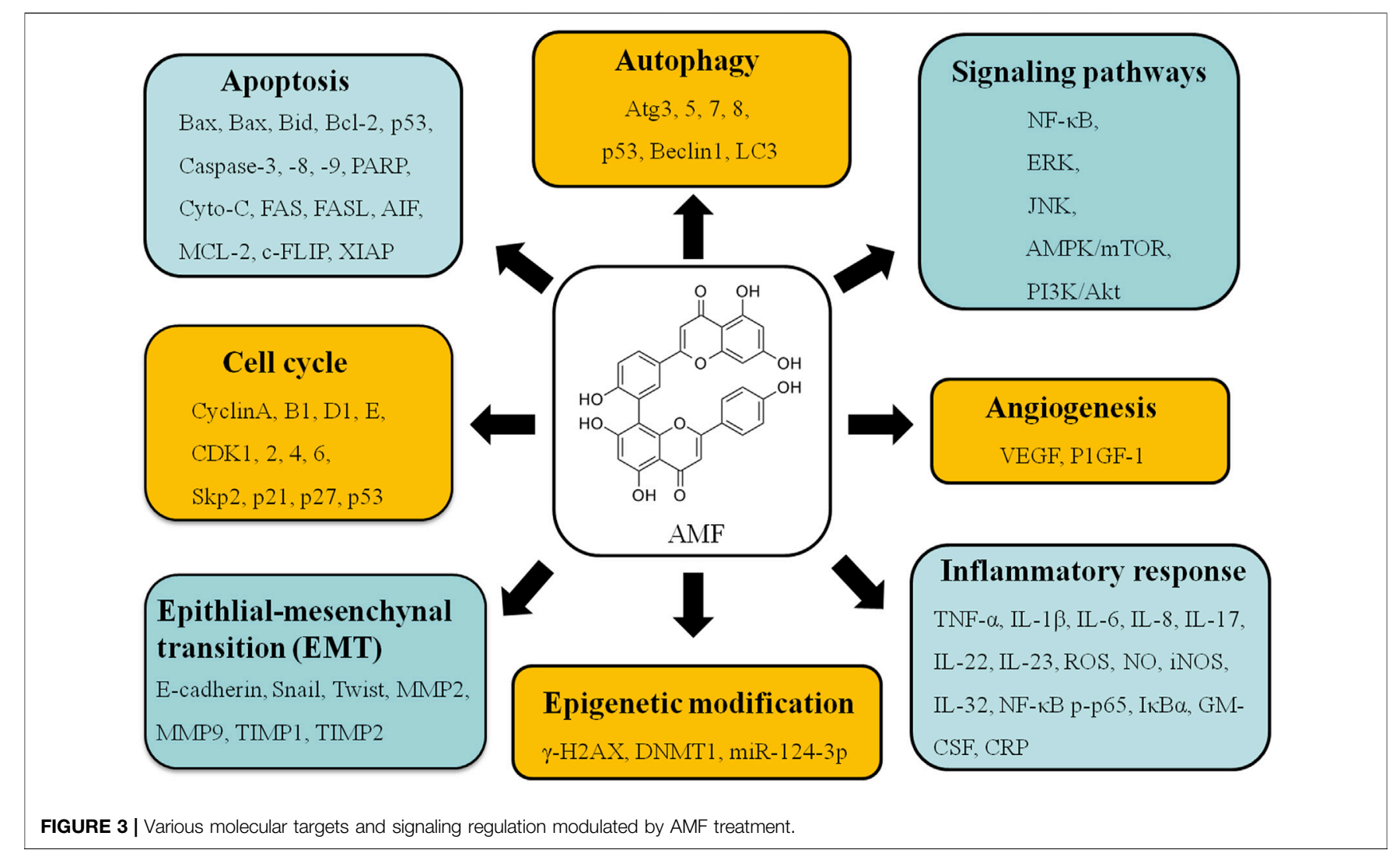

2020b). Moreover, AMF enhances insulin resistance in HepG2 cells and the underlying mechanisms may be involved in inflammatory cytokine expression, the processes of glucose oxygenolysis, gluconeogenesis, glycogen synthesis and the PI3K-Akt signaling pathway (Zheng et al., 2016).

\section{THE TOXICITY OR UNDESIRABLE EFFECTS OF AMENTOFLAVONE}

In addition to the extensive studies on the pharmacological effects, the toxicity or undesirable effects of AMF are also reported (Table 3). Cytochrome P450 enzymes (CYPs) are the typical drug-metabolizing enzymes (phase I metabolism). CYP enzymes are responsible for the breakdown of xenobiotics and endogenous components, such as environmental compounds and drugs, into metabolites (Kimura et al., 2010). Several studies have reported that the interaction of AMF with drugs inhibits the catalytic activities of CYP enzymes (von Moltke et al., 2004; Chaudhary and Willett, 2006; Kimura et al., 2010; Park et al., 2020). It is reported that AMF is a highly potent inhibitor of CYP2C9 with an $\mathrm{IC}_{50}$ value of $0.035 \mu \mathrm{M}$, and also inhibites CYP2C19, CYP 2D6 and CYP $3 \mathrm{~A}$ with $\mathrm{IC}_{50}$ values of 23.6, 24.3, 4.8 $\mu \mathrm{M}$, respectively (von Moltke et al., 2004). The 
calculated $\mathrm{IC}_{50}$ for CYP1A1 $(38 \pm 19 \mu \mathrm{M})$ by AMF is higher than the calculated $\mathrm{IC}_{50}$ for CYP1B1 $(4.6 \pm 1.4 \mu \mathrm{M})$ through regression curves plotting percent EROD inhibition. AMF inhibits CYP1A1with $K i$ value of $1.6 \pm 0.78 \mu \mathrm{M}$ in uncompetitive manner and CYP1B1 with $K i$ value of $0.99 \pm 0.31 \mu \mathrm{M}$ in competitive manner by EROD activity assay (Chaudhary and Willett, 2006). AMF displays a competitive-non-competitive mixed type of inhibition on CYP2C9 or CYP3A4 by Lineweaver-Burk plot analysis with $\mathrm{IC}_{50}$ values of 0.03 and $0.07 \mu \mathrm{M}$, respectively. The Lineweaver-Burk plots, secondary reciprocal plots and Dixon plots researches in human liver microsomes (HLMs) reveal that AMF strongly inhibits CYP1A2, CYP2A6, CYP2B6, CYP2C8, CYP2C9, CYP2C19, CYP2D6, CYP2E1 and CYP3A activity with $\mathrm{IC}_{50}$ values of 4.4, $11.9,7.1,0.084,0.15,3.4,2.6,3.3$ and $1.3 \mu \mathrm{M}$, respectively. AMF inhibits CYP2C8-mediated amodiaquine $\mathrm{N}$-deethylation activity with $K i$ value of $0.083 \mu \mathrm{M}$ in noncompetitive-dependent manner (Park et al., 2020).

UDP-glucuronosyl transferases (UGTs), the most important class of detoxification enzymes, are known as human phase II drug metabolizing enzymes (Lv et al., 2018). UGTs play key roles in the detoxification and metabolic elimination of a wide variety of endogenous compounds. The effects of AMF on UGTs (including UGT1A1, UGT1A3, UGT1A4, UGT1A6, UGT1A7, UGT1A8, UGT1A9, UGT1A10, UGT2B4, and UGT2B17) are carefully revealed that the $\mathrm{IC}_{50}$ values and $K i$ s of $\mathrm{AMF}$ against various human UGTs with ranging from 0.12 to $16.81 \mu \mathrm{M}, 0.29$ to $11.51 \mu \mathrm{M}$, respectively. In addition, AMF is a noncompetitive inhibitor of UGT1A1 mediated NCHN-O-glucuronidation, a competitive inhibitor of UGT1A4 mediated TFP-Nglucuronidation, a competitive inhibitor of UGT1A1 mediated 4-MU-O-glucuronidation and a competitive inhibitor of UGT1A9 mediated propofol or 4-MU-O-glucuronidation (Lv et al., 2018).

Besides those, Chiolbi et al. (1991) investigate that AMF can act at the initiation stage of $\mathrm{CCl} 4$-induced rat liver microsomal lipid peroxidation by interfering with the metabolism of $\mathrm{CCl} 4$. AMF is a potent inhibitor of TBA-reactive material formation with $\mathrm{IC}_{50}$ value of $74.1 \pm 0.8 \mu \mathrm{M}$ (Cholbi et al., 1991). Lee et al. (1996) reveal that AMF inhibits the PLCy1 activity with an IC $_{50}$ of $29 \mu \mathrm{M}$ and also reduces intracellular total inositol phosphates (lPt) in PDGF-treated NIH3T3yl cells with an IC50 of $9.2 \mu \mathrm{M}$. Lipolysis in fat cells is regulated by cAMP synthesis which is stimulated by adenylate cyclase activation or the reduction of cAMP destruction by phosphodiesterase (PDE) inhibition. Saponara and Bosisio (1998) demonstrate that AMF is a potent inhibitor on adipocyte-derived $\mathrm{PDE}$ with the $\mathrm{IC}_{50}$ value of $0.27 \mu \mathrm{M}$ in rat adipose tissue. AMF is proved to be a selective inhibitor of cyclooxygenase (COX)-1 catalysed prostaglandin biosynthesis with an $\mathrm{IC}_{50}$ value of $12.4 \mu \mathrm{M}$ in vitro (Bucar et al., 1998). Cathepsin B (CatB), a lysosomal cysteine protease, plays roles in intracellular protein catabolism and in other physiological processes (e.g., hormone activation, processing of antigens in the immune response and bone turnover) (Pan et al., 2005). Pan et al. (2005) report that AMF has a strong inhibitory activity against human CatB with a $\mathrm{IC}_{50}$ value of $1.75 \mu \mathrm{M}$. Inhibition of protein tyrosine phosphatase $1 \mathrm{~B}$
(PTP1B) has been proposed as a strategy for the treatment of type 2 diabetes and obesity ( $\mathrm{Na}$ et al., 2007). Na et al. (2007) suggest that AMF inhibits PTP1B with an $\mathrm{IC}_{50}$ value of $7.3 \pm 0.5 \mu \mathrm{M}$ and is a non-competitive inhibitor with a $K i$ value of $5.2 \mu \mathrm{M}$ by Kinetic study. Moreover, AMF shows strong inhibitory activity against $\beta$-secretase (BACE-1) with $\mathrm{IC}_{50}$ values of $1.54 \mu \mathrm{M}$ and can result in accumulation and deposition of amyloid $\beta(\mathrm{A} \beta)$ peptides in Alzheimer's disease (Sasaki et al., 2010). AMF inhibits JAK2 activity in a dose-dependent manner with an $\mathrm{IC}_{50}$ value of $5 \mu \mathrm{M}$ (Ma et al., 2014). AMF also shows strong inhibition on OAT3, a member of the solute carrier family of membrane transporters, with an $\mathrm{IC}_{50}$ of $2.0 \mu \mathrm{M}$ (Qiao et al., 2019). $\beta$-glucuronidase (GUS) plays a pivotal role in the metabolism and reactivation of a vast of glucuronide conjugates of both endogenous and xenobiotic compounds (Tian et al., 2021). AMF inhibits GUS-mediated SN38G and DDAOG hydrolysis with the $\mathrm{IC}_{50}$ values of 0.49 and $0.62 \mu \mathrm{M}$, respectively. AMF is a competitive type inhibitor for GUS-mediated SN38G hydrolysis and displays a mixed type inhibition against GUS-mediated DDAOG hydrolysis with the $K i$ values of 1.25 and $0.24 \mu \mathrm{M}$ by inhibition kinetics studies, respectively (Tian et al., 2021).

\section{MOLECULAR DOCKING SIMULATION OF AMENTOFLAVONE THROUGH IN SILICO APPROACH}

Molecular docking and molecular dynamics simulation are algorithm-based virtual screening methods searching for candidate drugs or molecules in a short time and serving for experimental studies (Alonso et al., 2006; De Vivo et al., 2016; Wang and Zhu, 2016). As a potential molecule with the activities of anti-inflammation (i.e., p38 MAPK signaling pathway) (Kadam et al., 2007), anti-tubercular (i.e., tuberculosis) (Nayak et al., 2018; Kumar et al., 2019), anti-chagas (Marinho et al., 2021) and anti-virus (i.e., SARS-CoV-2) (Ghosh et al., 2020; Lokhande et al., 2020), AMF is virtually screened through molecular docking and molecular dynamics simulation of in silico approaches in recent researches (Table 4).

It is reported that a powerful bond between p38 MAPK signaling pathway and inflammation (Lee et al., 1994). Kadam et al. (2007) explored the potential inhibitory effect of AMF on p38 MAPK using in silico study. The docking model predicts that AMF has a more favorable $\Delta \mathrm{G}$ binding of $-26.34 \mathrm{kcal} / \mathrm{mol}$ to $\mathrm{p} 38$ MAPK than the reported p38 MAPK inhibitor $(-17.95 \mathrm{kcal} / \mathrm{mol})$. AMF shows H-bonding which interacts with Met109, Lys53, Glu71, Val30 and Arg173, the carbonyl oxygen of $\gamma$-Benzopyrone ring which makes $\pi$-stacking interactions with Tyr35, and $\gamma$-benzopyrone 2-phenol group which binds to the selectivity pocket by HOMO/LUMO and surface analysis (HD and MESP) (Kadam et al., 2007).

Tuberculosis (TB) has prevailed for millennia and remains a major health problem worldwide (Sabiiti and consortium, 2017). Increasing incidences of multidrug resistant cases of $\mathrm{TB}$ are a major threat. AMF is reported to have antibacterial and antitubercular activities (Nayak et al., 2018; Kumar et al., 2019). In silico screening, Nayak et al. (2018) and Kumar et al. 
TABLE 3 | The inhibitory effects of AMF on different enzymes (targets).

\begin{tabular}{|c|c|c|c|c|}
\hline Substrate & Enzyme (target) source & IC50 ( $(\mu \mathrm{M})$ & $\mathbf{K i}(\mu \mathrm{M})$ & Refences \\
\hline TBA & Microsomal lipid peroxidation & $74.1 \pm 0.8$ & & Cholbi et al. (1991) \\
\hline $\mathrm{IP}_{\mathrm{t}}$ & pLCr1 & 29 & & Lee et al. (1996) \\
\hline \multirow[t]{2}{*}{ cAMP } & Phosphodiesterase (PDE) & 0.27 & & Saponara and Bosisio, (1998) \\
\hline & $\mathrm{COX}-1$ & 12.4 & & Bucar et al. (1998) \\
\hline Flurbiprofen & CYP29C & 0.035 & & von Moltke et al. (2004) \\
\hline S-Mephenytoin & CYP2C19 & 23.6 & & \\
\hline Dextromethorphan & CYP2D6 & 24.3 & & \\
\hline \multirow[t]{2}{*}{ Triazolam } & CYP3A & 4.8 & & \\
\hline & Cathepsin B & 1.75 & & Pan et al. (2005) \\
\hline \multirow[t]{2}{*}{ EROD } & CYP1A1 & $38 \pm 19$ & $1.6 \pm 0.78$ & Chaudhary and Willett, (2006) \\
\hline & CYP1B1 & $4.6 \pm 1.4$ & $0.99 \pm 0.31$ & \\
\hline \multirow[t]{2}{*}{ Insulin receptor } & PTP1B & 7.3 & 5.2 & Na et al. (2007) \\
\hline & $\beta$-secretase (BACE-1) & 1.54 & & Sasaki et al. (2010) \\
\hline Diclofenac & CYP2C9 & 0.03 & 0.007 & Kimura et al. (2010) \\
\hline \multirow[t]{2}{*}{ Testosterone } & CYP3A4 & 0.07 & 0.027 & \\
\hline & JAK2 & 5 & & Ma et al. (2014) \\
\hline \multirow[t]{11}{*}{ 4-MU-O-glucuronidation } & UGT1A1 & $0.78 \pm 0.19$ & $2.21 \pm 1.14$ & Lv et al. (2018) \\
\hline & UGT1A3 & $2.55 \pm 0.07$ & $0.73 \pm 0.31$ & \\
\hline & UGT1A6 & $3.43 \pm 0.83$ & $4.05 \pm 0.21$ & \\
\hline & UGT1A7 & $0.12 \pm 0.02$ & $0.29 \pm 0.03$ & \\
\hline & UGT1A8 & $1.72 \pm 0.54$ & $0.85 \pm 0.15$ & \\
\hline & UGT1A9 & $4.54 \pm 0.63$ & $0.46 \pm 0.12$ & \\
\hline & UGT1A10 & $2.71 \pm 0.43$ & $3.45 \pm 0.59$ & \\
\hline & UGT2B4 & $7.06 \pm 0.82$ & $5.18 \pm 2.06$ & \\
\hline & UGT2B7 & $15.91 \pm 4.85$ & $11.51 \pm 5.24$ & \\
\hline & UGT2B15 & $16.86 \pm 5.67$ & $9.88 \pm 0.94$ & \\
\hline & UGT2B17 & $2.13 \pm 0.23$ & $2.16 \pm 1.57$ & \\
\hline $6-\mathrm{CF}$ & OAT3 & 2 & & Qiao et al. (2019) \\
\hline Phenacetin & CYP1A2 & 4.4 & $3.1 \pm 0.6$ & Park et al. (2020) \\
\hline Coumarin & CYP2A6 & 11.9 & & \\
\hline Bupropion & CYP2B6 & 7.1 & $7.9 \pm 1.1$ & \\
\hline Amodiaquine & CYP2C8 & 0.084 & $0.018 \pm 0.002$ & \\
\hline Diclofenac & CYP2C9 & 0.15 & $0.032 \pm 0.007$ & \\
\hline Omeprazole & CYP2C19 & 3.4 & & \\
\hline Dextromethorphan & CYP2D6 & 2.6 & & \\
\hline Chlorzoxazone & CYP2E1 & 3.3 & & \\
\hline Midazolam & CYP3A & 1.3 & $4.5 \pm 0.5$ & \\
\hline DDAOG & $\beta$-glucuronidase & 0.62 & 0.24 & Tian et al. (2021) \\
\hline SN38G & & 0.49 & 1.25 & \\
\hline
\end{tabular}

(2019) identify that AMF can target the drugs of Mycobacterium tuberculosis (MTB) and possesses anti-TB activity. Mycobacterium tuberculosis uridine diphosphate galactofuranose galactopyranose mutase (UGM) is not only a necessary flavoenzyme for the survival of mycobacteria, but also an important part of cell wall (Nayak et al., 2018). Nayak et al. (2018) find that AMF is a potential effective inhibitor against UGM by virtual screening and interaction analysis. AMF shows a high binding affinity (binding energy of $-10.4 \mathrm{kcal} / \mathrm{mol}$ ) toward UGM and has hydrogen bond interactions with the residues Glu143, Phe157, Trp166, Asn177, Asn282 (Nayak et al., 2018). Meanwhile, Kumar et al. (2019) proclaim that fifteen proteins which are actively involved in molecular function, biological process and cellular component of MTB are shortlisted by virtual screening. Nevertheless, only five drugs of MTB (i.e., Ask, DdlA, PanC, RplW, and TrpB) are inhibited by AMF according to in silico analysis (Kumar et al., 2019). AMF inhibits Ask with binding energy of $-9.9 \mathrm{kcal} / \mathrm{mol}$ by interacting with Leu212, Thr156, Ala205, Leu214, and Arg355 of Ask to form polar contact. The residues Glu23, Ser201, Lys194, Arg316, and Asn329 of DdlA protein can interact with AMF to form polar contact with binding energy of $-10.7 \mathrm{kcal} / \mathrm{mol}$ (Kumar et al., 2019). Further, AMF interacts with His44, Lys160, Gly46, and Asn69 of PanC protein to form $\mathrm{H}$-bonds with binding energy of $-10.7 \mathrm{kcal} / \mathrm{mol}$ (Kumar et al., 2019). AMF binds with RplW with an affinity of $-7.4 \mathrm{kcal} / \mathrm{mol}$ by forming polar contacts with Ile49 and Asp94 residues (Kumar et al., 2019). AMF can also binds with TrpB well with an affinity of $-9.7 \mathrm{kcal} / \mathrm{mol}$ and forms polar contacts with residues of Gly247, Asp319, Gly248, Ala126, Thr204, His129, and Arg155 residues in protein-ligand complex (Kumar et al., 2019).

Cruzain is a main cysteine protease enzyme of T. cruzi and essential for intracellular parasite replication. It is considered one of the most important targets for new trypanocidal agent development (Avelar et al., 2015). Cruzain has a catalytic site locating at the intersection of two domains, namely $\alpha$-helices and $\beta$-Sheets, in which the residues are prominent. The molecular docking analysis shows that AMF has an interactive affinity 
TABLE 4 | Molecular docking proteins of AMF through in silico study.

\begin{tabular}{|c|c|c|c|}
\hline Proteins & $\begin{array}{l}\text { Binging energy } \\
\text { (Kcal/mol) }\end{array}$ & Interacting residues & References \\
\hline P38 MAPK & -26.34 & Val30, Tyr35, Met109, Glu71, Arg173, Lys53 & Kadam et al. (2007) \\
\hline UGM & -10.4 & Glu143, Phe157, Trp166, Asn177, Asn282 & Nayak et al. (2018) \\
\hline Ask & -9.9 & Thr156, Leu214, Leu212, Ala205, Arg355 & (Kumar et al., 2019) \\
\hline DdlA & -10.7 & Lys194, Asn329, Arg316, Glu23, Ser201 & \\
\hline PanC & -10.7 & Gly46, Lys160, His44, Asn69 & \\
\hline RplW & -7.4 & lle49, Asp94 & \\
\hline TrpB & -9.7 & Arg155, Ala126, Asp319, His129, Thr204, Gly248, Gly247 & \\
\hline Cruzain & -8.0 & $\begin{array}{l}\text { Gln159, Gln19, Leu160, Met145, Asp161, Gln21, His162, Gly20, Met68, } \\
\text { Gly163, Trp26, Gly65, Ala138, Ser64, Cys25, Gly23, Trp184 }\end{array}$ & Marinho et al. (2021) \\
\hline $\begin{array}{l}\text { SARS Cov-3-Chymotrypsin-like } \\
\text { protease (3CLpro) }\end{array}$ & -11.42 & Leu141, His163, Gln189, Gln192, Val186 & Ryu et al. (2010) \\
\hline $\begin{array}{l}\text { SARS Cov-2-3-Chymotrypsin-like } \\
\text { protease (3CLpro) }\end{array}$ & -9.4 & $\begin{array}{l}\text { His41, Arg188, Cys44, Met49, Phe140, Asn142, Leu141, Val186, } \\
\text { Cys145, Met165, Asp187, Glu166, Gln189 }\end{array}$ & Swargiary et al. (2020) \\
\hline SARS Cov-2-main protease (Mpro) & -9.2 & $\begin{array}{l}\text { Thr26, Glu166, Thr25, Tyr54, His172, Leu27, Leu42, Arg188, Asn142, } \\
\text { Gly143, Ser144, His164, Leu167, Pro168, His163, Phe140, Cys145, } \\
\text { Leu141, Asp187, Gln189, Met165, His41 }\end{array}$ & Ghosh et al. (2020) \\
\hline SARS Cov-2-main protease (Mpro) & -27.0441 & Thr26, Asn142, His163, Glu166 & Lokhande et al. (2020) \\
\hline SARS-CoV-2-main protease (Mpro) & -10.0 & Leu141, Thr45, Thr190, Asn142, Glu166, Cys44 & Saravanan et al. (2020) \\
\hline SARS-CoV-2-main protease (Mpro) & -9.7 & Glu166, Glu189, Asn142, Ser144, Cys145, Leu141, Gly143 & Puttaswamy et al. (2020) \\
\hline SARS-CoV-2-main protease (Mpro) & -7.589 & Glu66, Thr25, His41, Ser46 & Patil et al. (2021) \\
\hline SARS-CoV-2-main protease (Mpro) & -8.1 & Asn151, His246 & Rameshkumar et al. (2021) \\
\hline SARS-CoV-2-spike protein & -7.6 & Arg457, Ser469, Glu471, Lys458, Asp467 & Wei et al. (2020) \\
\hline SARS-CoV-2-spike protein & -8.7 & $\begin{array}{l}\text { Gln493, Ser494, Gly496, Gln498, Tyr495, Arg403, Glu493, Asn501, } \\
\text { Try453, Tyr505, Leu455, Gly502, Lys417 }\end{array}$ & Puttaswamy et al. (2020) \\
\hline SARS-CoV-2-spike protein & -8.5 & Tyr453, Arg403, Gly496, Asn501, Gln498, Tyr505, Tyr495 & $\begin{array}{l}\text { Miroshnychenko and } \\
\text { Shestopalova, (2021) }\end{array}$ \\
\hline SARS-CoV-2-spike protein & -10.2 & Val315, Thr319, Thr394, Phe396, Asn628 & Rameshkumar et al. (2021) \\
\hline $\begin{array}{l}\text { SARS-CoV-2-RNA-dependent RNA } \\
\text { polymerase (RdRp) }\end{array}$ & -8.1 & Ser43, Asp350, Tyr385, Asn394 & Rameshkumar et al. (2021) \\
\hline
\end{tabular}

simulations $(-8.0 \mathrm{kcal} / \mathrm{mol})$ with the catalytic site of cruzain (Marinho et al., 2021). The interactions between AMF and cruzain are identified. They are three hydrogen bonds with the residues Gly20, Met68 and Ser64, a van der Waals with His162, an Amide-Pi with the Asp161, a Pi-Alkyl with Ala138, and a $\pi-\pi$ stacking with Trp184 (Marinho et al., 2021).

\section{ANTI-SARS-COV-2 EFFECT OF AMENTOFLAVONE}

Coronavirus disease (COVID-19) is an infectious disease caused by severe acute respiratory syndrome coronavirus 2 (SARS-CoV2). SARS-CoV-2 primarily infects the lungs and causes certain types of pneumonia-like symptoms (Huang et al., 2020; Kumar et al., 2021). COVID-19 is a communicable disease and is spreading internationally. SARS-CoV-2 is a member of coronavirus family and belongs to the beta-coronavirus $2 \mathrm{~B}$ lineage (Lai et al., 2020). SARS-CoV-2 is composed of four structural proteins [spike $(\mathrm{S})$, membrane $(\mathrm{M})$, envelope (E), nucleocapsid $(\mathrm{N})$ proteins] and sixteen nonstructural proteins (Nsp1-16) (Wang et al., 2020). Spike protein, the most variable structure, is a heavily glycosylated protein and has a receptor binding domain (RBD) (Zhou et al., 2020) which can mediates coronavirus entry into host cells (Bosch et al., 2003; Li, 2016). The main protease (Mpro/3CLpro) in Nsp5 participates in the process of polyproteins which play a critical role in the replication and transcription of SARS-CoV-2 (Kirtipal et al., 2020; Wang et al., 2020). The RNA-dependent RNA polymerase (RdRp) locates in Nsp12 which also participates in the replication/transcription of coronavirus (Kirtipal et al., 2020; Wang et al., 2020). The spike protein mediates SARS-CoV-2 to invade host cells. Moreover, the main protease and $\mathrm{RdRp}$ participates in the replication/ transcription of SARS-CoV-2 (Kirtipal et al., 2020; Wang et al., 2020). Therefore, the spike protein, main protease, and RdRp are important drug targets of anti-SARSCoV-2.

Many previous studies have found that AMF can form a complex with the spike protein, Mpro and RdRp of SARSCoV-2 (Lokhande et al., 2020; Puttaswamy et al., 2020; Rameshkumar et al., 2021) (Table 4; Figure 4). Lokhande et al. (2020) suggest that AMF has a strong binding affinity $(-27.0441 \mathrm{kcal} / \mathrm{mol})$ towards SARS-CoV-2-Mpro by the molecular docking analysis. Further, they reveal that AMF is highly stable and is of less conformational fluctuations with the Mpro enzyme through molecular dynamic simulations (Lokhande et al., 2020). Similarly, Ghosh et al. (2020) confirm that AMF interacts with two important catalytic residues (His41 and Cys145) of SARS CoV-2-Mpro, and exhibits higher binding affinity $(-9.2 \mathrm{kcal} / \mathrm{mol})$ towards Mpro than those of two wellknown Mpro inhibitors N3 $(-7.0 \mathrm{kcal} / \mathrm{mol})$ and lopinavir $(-7.3 \mathrm{kcal} / \mathrm{mol})$. Molecular dynamics studies further reveals that AMF is of highly stability, less conformational fluctuations and shares a similar degree of compactness (Ghosh et al., 2020). Saravanan et al. (2020) find that AMF shows highly binding 


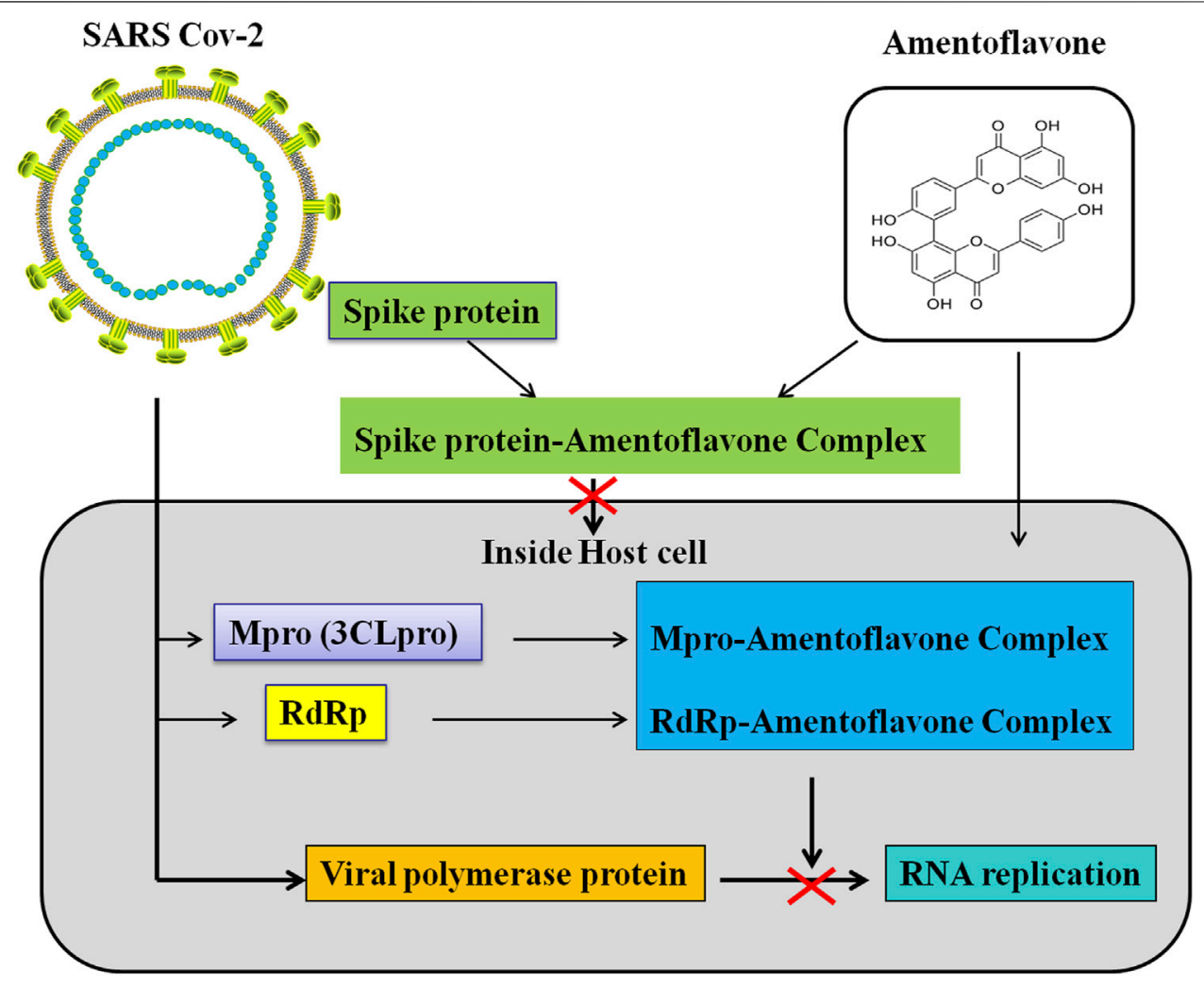

FIGURE 4 | Schematic representation for the functions of AMF in SARS-Cov 2 replication and transcription.

energy of $-10.0 \mathrm{kcal} / \mathrm{mol}$ and stable interaction after binding with the SARS-COV2 main protease. AMF records $-9.7 \mathrm{kcal} / \mathrm{mol}$ of binding energy against Mpro and interacts with target AAR by forming $\mathrm{H}$ bonds with Glu166 and other residues in the vicinity of catalytic site (Puttaswamy et al., 2020). AMF has a docking score of $-7.766 \mathrm{kcal} / \mathrm{mol}$ which points out a strong bind with SARSCoV-2 main protease (Mpro). AMF forms hydrogen bond (HB) interactions with Glu166, Thr25, His41 and Ser46 residues, and also forms a $\pi-\pi$ stacking interaction with His41 residue (Patil et al., 2021). AMF exhibits a binding affinity of $-8.1 \mathrm{kcal} / \mathrm{mol}$ and key amino acids including Asn151 and His246 are involved in the hydrogen bond (HB) interactions (Rameshkumar et al., 2021). In addition, AMF is also found to have strongly binding affinity $(-9.4 \mathrm{kcal} / \mathrm{mol})$ with SARS CoV-2 3CLpro, and can stabilize the three-dimensional conformations of 3CLpro after binding (Swargiary et al., 2020). There are also four docking studies targeting spike glycoprotein RBD of SARS-CoV-2. These studies reveal that AMF can strong bind with spike glycoprotein RBD of SARS-CoV-2 with the binding energies: $-7.6 \mathrm{kcal} / \mathrm{mol}$ (Wei et al., 2020), $-8.7 \mathrm{kcal} / \mathrm{mol}$ (Puttaswamy et al., 2020), $-8.5 \mathrm{kcal} / \mathrm{mol}$ (Miroshnychenko and Shestopalova (2021)) and $-10.2 \mathrm{kcal} / \mathrm{mol}$ (Rameshkumar et al., 2021). However, the binding sites of AMF are different in these studies. Wei et al. (2020) and Rameshkumar et al. (2021) suggest that AMF binds with the outside of the ACE2-binding region, while Miroshnychenko and Shestopalova, (2021). and Puttaswamy et al. (2020) reveal that AMF binds with the ACE2-binding region. Besides AMF binds with the main protease $(-8.1 \mathrm{kcal} /$ $\mathrm{mol})$ and spike protein $(-10.2 \mathrm{kcal} / \mathrm{mol})$ of SARS-CoV-2, AMF can also bind with RNA-dependent RNA polymerase (RdRp) with a binding affinity of $-8.1 \mathrm{kcal} / \mathrm{mol}$ (Rameshkumar et al., 2021). Altogether, the above-mentioned studies in silico approaches suggest that AMF could be a potential inhibitor of SARS-CoV-2 proteins (i.e., Mpro/3CLpro, RBD of Spike protein, and RNA-dependent RNA polymerase) and an effective drug candidate for SARS-CoV-2.

\section{BIOAVILABILITY AND DRUG DELIVERY OF AMENTOFLAVONE}

AMF is a hydrophobic molecule and practically insoluble in water. To defeat the water insolubility and low bioavailability of AMF, some potential efficient drug delivery carriers which can wrap AMF inside are developed, such as the $\mathrm{N}$-vinyl pyrrolidonemaleate-guerbet alcohol monoester polymer [P(NVP-MGAM)] micelles (Zhang et al., 2019), the amorphous solid dispersion (ASD) with polyvinylpyrrolidone K-30 (PVP K-30) (Chen et al., 2020a) and AMF-loaded vitamin E polyethylene glycol succinate (TPGS)/soluplus mixed micelles (Feng et al., 2020) (Table 5). These drug delivery carriers have effectively improved the solubility and bioavailability of AMF.

$\mathrm{P}$ (NVP-MGAM)/AMF micelle is produced to load AMF into the P (NVPMGAM) micelle by the dialysis method (Zhang et al., 
TABLE 5 | various drug delivery carriers containing amentoflavone.

\begin{tabular}{|c|c|c|c|}
\hline Carrier & Model system & Inference & References \\
\hline $\begin{array}{l}\text { N-vinyl pyrrolidone-maleate-guerbet alcohol } \\
\text { monoester polymer [P(NVP-MGAM)] }\end{array}$ & $\begin{array}{l}\text { KKAy insulin resistant diabetes mice } \\
\text { models }\end{array}$ & $\begin{array}{l}\mathrm{P}(\mathrm{NVP}-\mathrm{MGAM}) / \mathrm{AMF} \text { micelles enhance the oral bioavailability of } \\
\text { amentoflavone, and is a potent drug for diabetes treatment }\end{array}$ & $\begin{array}{l}\text { Zhang et al. } \\
\text { (2019) }\end{array}$ \\
\hline $\begin{array}{l}\text { amorphous solid dispersion (ASD) with } \\
\text { polyvinylpyrrolidone K-30 }\end{array}$ & $\begin{array}{l}\text { A549 xenograft-bearing mice } \\
\text { models }\end{array}$ & $\begin{array}{l}\text { ASD is an efficient drug delivery system, and reduce in tumor } \\
\text { size and microvascular density occurred }\end{array}$ & $\begin{array}{l}\text { Chen et al. } \\
(2020 a)\end{array}$ \\
\hline TPGS/soluplus mixed micelles & $\begin{array}{l}\text { A549 cells in vitro, Sprague-Dawley } \\
\text { (SD) male rats in vivo }\end{array}$ & $\begin{array}{l}\text { AMF-loaded mixed micelles have lower IC50 value to A549 cells } \\
\text { in the cytotoxicity test, and increase metabolites in plasma and } \\
\text { urine in rats }\end{array}$ & $\begin{array}{l}\text { Feng et al. } \\
\text { (2020) }\end{array}$ \\
\hline
\end{tabular}

2019). Compared with AMF suspension group, P (NVPMGAM)/AMF micelle group not only improves pharmacokinetic parameters, such as delaying the Tmax, prolonging the retention time in blood and increasing the area under the curve (AUC), but also increases tissue distribution. This result indicates that the $\mathrm{P}$ (NVP-MGAM)/AMF micelle is an efficient AMF delivery carrier which can slow AMF metabolism and enhance AMF bioavailability. Additionally, The accumulation of P (NVP-MGAM)/AMF micelle shows a better antidiabetic efficacy by activating the PPAR- $\gamma$ and PI3K/Akt signaling pathway comparing with AMF suspension in KKAy insulin resistant diabetes mice (Zhang et al., 2019). As a windfall benefit, $\mathrm{P}$ (NVP-MGAM)/AMF micelle may be a potent drug for diabetes mellitus treatment.

Selaginella doederleinii (TBESD, containing five active ingredients: AMF, robustaflavone, 2",3"-dihydro-3', $3^{\prime \prime \prime}$ biapigenin, $3^{\prime}, 3^{\prime \prime \prime}$-binaringenin and delicaflavone) amorphous solid dispersion (TBESD-ASD) with polyvinylpyrrolidone K-30 (PVP K30) is successfully established by the solvent evaporation method. TBESD-ASD with PVP K-30 shows a higher dissolution rate and stability than free TBESD. Moreover, the absorption and bioavailability of TBESD-ASD are substantially higher than free TBESD by comparing the pharmacokinetic parameters (such as mean Cmax, MRT values, and AUC). In xenograft mice transplanted with A549 cells, the TBESD-ASD exhibits greater antitumor effect than free TBESD by blocking tumor angiogenesis (Chen et al,, 2020a). These results demonstrate that ASD is an efficient drug delivery carrier for TBESD and can improve the bioavailability of TBESD.

AMF-loaded TPGS/soluplus mixed micelle is prepared by membrane hydration method (Zhao et al., 2017a; Feng et al., 2020). In vitro, AMF-loaded TPGS/soluplus mixed micelle shows higher toxicity to A549 cells than AMF. In rats, 14 metabolites including 11 in feces, 6 in urine, and 3 in plasma in AMF-loaded mixed micelle group are found, while only 3 metabolites in urine and no metabolites in plasma and bile of AMF group were found (Feng et al., 2020). TPGS/soluplus drug nanomicelle carrier successfully improves the bioavailability of AMF.

\section{CLINICAL PROSPECTIVE}

In this review, we suggest that AMF, a natural biflavonoid compound with extensive pharmacological effects, is a potential drug candidate. Various studies have shown the potential application of AMF against dengue, herpes, candidiasis, chronic hepatitis and other infect diseases. In addition, AMF can inhibit the proteolytic/catalytic activity of SARS CoV-2 Mpro/spike protein/RdRp and might be a useful therapeutic drug to control SARS-CoV-2. AMF might be a potential therapeutic agent for prevention and/or treatment of UV and $\gamma$-irradiation induced damage. Furthermore, the neuroprotective effect of AMF is evident in its ability to against neurodegenerative diseases, including ischemic stroke, epilepsy, Parkinson's disease, Alzheimer's disease. AMF has also excellent potential therapeutic agent against bone diseases such as osteoporosis, rheumatoid arthritis, osteoarthritis. Numerous researches on AMF have revealed its cytotoxic potential against different cancers, such as HCC, breast cancer, osteosarcoma, bladder cancer, ovarian cancer, etc. AMF suppresses tumor pathological progress and metastasis in vitro and in vivo through several molecular mechanisms, including cell cycle arrest, apoptosis and autophagy induction, etc. AMF acts anti-cancer effect also by initiating p53 and inhibiting NF- $\mathrm{kB}$, PI3K-AKT, ERK, and MAPK/mTOR signal pathways. Being a natural antioxidant and antibacterial agent in the food industry, AMF could be a potential use to improve the nutritional quality of food or processed food products.

Various animal researches strongly advocate the potential role of AMF in controlling tumor development, metabolic disorders, skeletal diseases and nerve protection. However, there is no clinical research investigation on the efficacy of AMF by now. Since AMF widely exists in nature, its utilization can greatly economize expenses related to growing diseases. As the improvement of delivery system, the absorption and bioavailability of AMF are significantly increased. In future, the preclinical and clinical studies are crucial for us to exploit the therapeutic potential of AMF and will help us to apply the active compound to the clinic.

\section{CONCLUSION}

This review discussed the multiple biological activities of AMF revealed in the past 40 years. AMF improves inflammation by inhibiting the activation of NF-KB signaling pathway and the downstream target genes. AMF protects neurological and skeletal diseases because of its anti-oxidative and anti-inflammatory activities. In addition, AMF restores the imbalance of lipid and carbohydrate metabolism and reverses DNA damage caused by radiation. AMF increases the expression of apoptosis and 
autophagy-related proteins, inhibits the expression of cell cycle, metastasis-associated proteins, and led to control cancer development. In Silico, AMF is forecasted to bind tightly with the spike, Mpro and RdRp proteins of SARS-CoV-2. This implies that AMF is a potential drug for the treatment of COVID-19.

In summary, AMF may be a broad and effective multifunctional active agent in disease therapy.

\section{AUTHOR CONTRIBUTIONS}

Conceptualization, XX, ZL, YW, and AL; writing-original draft preparation, XX, NT and XL; writing-review and revision, ZL, YW and AL; figures and tables, JZ and WW; supervision, XL and

\section{REFERENCES}

Alfa, R. W., and Kim, S. K. (2016). Using Drosophila to Discover Mechanisms Underlying Type 2 Diabetes. Dis. Model Mech. 9 (4), 365-376. doi:10.1242/ dmm.023887

Aliyev, A., Ozcan-Sezer, S., Akdemir, A., and Gurer-Orhan, H. (2021). In Vitro evaluation of Estrogenic, Antiestrogenic and Antitumor Effects of Amentoflavone. Hum. Exp. Toxicol. 40, 1510-1518. doi:10.1177/ 0960327121999454

Alkadi, K. A., Ashraf, K., Adam, A., Shah, S. A., Taha, M., Hasan, M., et al. (2021). In Vitro Cytotoxicity and Anti-inflammatory Cytokinine Activity Study of Three Isolated Novel Compounds of Prismatomeris Glabra. J. Pharm. Bioall Sci. 13 (1), 116-122. doi:10.4103/jpbs.JPBS_279_19

Alonso, H., Bliznyuk, A. A., and Gready, J. E. (2006). Combining Docking and Molecular Dynamic Simulations in Drug Design. Med. Res. Rev. 26 (5), 531-568. doi:10.1002/med.20067

An, J., Li, Z., Dong, Y., Ren, J., and Huo, J. (2016). Amentoflavone Protects against Psoriasis-like Skin Lesion through Suppression of NF-Kb-Mediated Inflammation and Keratinocyte Proliferation. Mol. Cell Biochem 413 (1-2), 87-95. doi:10.1007/s11010-015-2641-6

Anand, K., Ziebuhr, J., Wadhwani, P., Mesters, J. R., and Hilgenfeld, R. (2003). Coronavirus Main Proteinase (3CLpro) Structure: Basis for Design of AntiSARS Drugs. Science 300 (5626), 1763-1767. doi:10.1126/science.1085658

Ashwal, S., and Pearce, W. J. (2001). Animal Models of Neonatal Stroke. Curr. Opin. Pediatr. 13 (6), 506-516. doi:10.1097/00008480-200112000-00003

Avelar, L. A., Camilo, C. D., de Albuquerque, S., Fernandes, W. B., Gonçalez, C., Kenny, P. W., et al. (2015). Molecular Design, Synthesis and Trypanocidal Activity of Dipeptidyl Nitriles as Cruzain Inhibitors. Plos Negl. Trop. Dis. 9 (7), e0003916. doi:10.1371/journal.pntd.0003916

Baglietto-Vargas, D., Shi, J., Yaeger, D. M., Ager, R., and LaFerla, F. M. (2016). Diabetes and Alzheimer's Disease Crosstalk. Neurosci. Biobehav Rev. 64, 272-287. doi:10.1016/j.neubiorev.2016.03.005

Bais, S., Abrol, N., Prashar, Y., and Kumari, R. (2017). Modulatory Effect of Standardised Amentoflavone Isolated from Juniperus Communis L. Agianst Freund's Adjuvant Induced Arthritis in Rats (Histopathological and X Ray Anaysis). Biomed. Pharmacother. 86, 381-392. doi:10.1016/j.biopha.2016.12.027

Bajpai, V. K., Park, I., Lee, J., Shukla, S., Nile, S. H., Chun, H. S., et al. (2019). Antioxidant and Antimicrobial Efficacy of a Biflavonoid, Amentoflavone from Nandina Domestica In Vitro and in Minced Chicken Meat and Apple Juice Food Models. Food Chem. 271, 239-247. doi:10.1016/j.foodchem.2018.07.159

Banerjee, T., Valacchi, G., Ziboh, V. A., and van der Vliet, A. (2002a). Inhibition of TNFalpha-Induced Cyclooxygenase-2 Expression by Amentoflavone through Suppression of NF-kappaB Activation in A549 Cells. Mol. Cell Biochem 238 (12), 105-110. doi:10.1023/a:1019963222510

Banerjee, T., Van der Vliet, A., and Ziboh, V. A. (2002b). Downregulation of COX2 and iNOS by Amentoflavone and Quercetin in A549 Human Lung Adenocarcinoma Cell Line. Prostaglandins Leukot. Essent. Fatty Acids 66 (56), 485-492. doi:10.1054/plef.2002.0387
AL All authors have read and agreed to the published version of the manuscript.

\section{FUNDING}

This study was financially supported by the National Natural Science Foundation of China (No. 81902802), the National Science Foundation of Guangdong Province (No. 2019A1515010633), Traditional Chinese Medicine Bureau of Guangdong Province (Nos. 20191258, 20191260, 20211298), Guangzhou Science and Technology Project (Nos. 202102010058, 202102010060) and Technology Project of Guangzhou Municipal Health Commission (No. 20201A011020).

Bonacorsi, C., Raddi, M. S., da Fonseca, L. M., Sannomiya, M., and Vilegas, W (2012). Effect of Byrsonima Crassa and Phenolic Constituents on Helicobacter Pylori-Induced Neutrophils Oxidative Burst. Int. J. Mol. Sci. 13 (1), 133-141. doi:10.3390/ijms13010133

Borchers, A. T., Chang, C., Gershwin, M. E., and Gershwin, L. J. (2013). Respiratory Syncytial Virus-Aa Comprehensive Review. Clin. Rev. Allergy Immunol. 45 (3), 331-379. doi:10.1007/s12016-013-8368-9

Bosch, B. J., van der Zee, R., de Haan, C. A., and Rottier, P. J. (2003). The Coronavirus Spike Protein Is a Class I Virus Fusion Protein: Structural and Functional Characterization of the Fusion Core Complex. J. Virol. 77 (16), 8801-8811. doi:10.1128/jvi.77.16.8801-8811.2003

Brazil, D. P., and Hemmings, B. A. (2001). Ten Years of Protein Kinase B Signalling: a Hard Akt to Follow. Trends Biochem. Sci. 26 (11), 657-664. doi:10.1016/s0968-0004(01)01958-2

Bucar, F., Jachak, S. M., Noreem, Y., Kartnig, T., Perera, P., Bohlin, L., et al. (1998). Amentoflavone from Biophytum Sensitivum and its Effect on COX-1/COX-2 Catalysed Prostaglandin Biosynthesis. Planta Med. 64 (4), 373-374. doi:10.1055/s-2006-957455

Cai, J., Zhao, C., Du, Y., Huang, Y., and Zhao, Q. (2019). Amentoflavone Ameliorates Cold Stress-Induced Inflammation in Lung by Suppression of C3/BCR/NF- $\mathrm{B}$ Pathways. BMC Immunol. 20 (1), 49. doi:10.1186/s12865-019-0331-y

Camacho, M. R., Mata, R., Castaneda, P., Kirby, G. C., Warhurst, D. C., Croft, S. L., et al. (2000). Bioactive Compounds from Celaenodendron Mexicanum. Planta Med. 66 (5), 463-468. doi:10.1055/s-2000-8598

Cao, B., Zeng, M., Zhang, Q., Zhang, B., Cao, Y., Wu, Y., et al. (2021) Amentoflavone Ameliorates Memory Deficits and Abnormal Autophagy in A 25 -35-Induced Mice by mTOR Signaling. Neurochem. Res. 46 (4), 921-934. doi:10.1007/s11064-020-03223-8

Cao, Q., Qin, L., Huang, F., Wang, X., Yang, L., Shi, H., et al. (2017). Amentoflavone Protects Dopaminergic Neurons in MPTP-Induced Parkinson's Disease Model Mice through PI3K/Akt and ERK Signaling Pathways. Toxicol. Appl. Pharmacol. 319, 80-90. doi:10.1016/j.taap.2017.01.019

Chakravarthy, B. K., Rao, Y. V., Gambhir, S. S., and Gode, K. D. (1981). Isolation of Amentoflavone from Selaginella Rupestris and its Pharmacological Activity on central Nervous System, Smooth Muscles and Isolated Frog Heart Preparations. Planta Med. 43 (1), 64-70. doi:10.1055/s-2007-971475

Chang, B. S., and Lowenstein, D. H. (2003). Epilepsy. N. Engl. J. Med. 349 (13), 1257-1266. doi:10.1056/NEJMra022308

Chaudhary, A., and Willett, K. L. (2006). Inhibition of Human Cytochrome CYP 1 Enzymes by Flavonoids of St. John's Wort. Toxicology 217 (2-3), 194-205. doi:10.1016/j.tox.2005.09.010

Chen, B., Wang, X., Zhang, Y., Huang, K., Liu, H., Xu, D., et al. (2020a). Improved Solubility, Dissolution Rate, and Oral Bioavailability of Main Biflavonoids from Selaginella Doederleinii Extract by Amorphous Solid Dispersion. Drug Deliv. 27 (1), 309-322. doi:10.1080/10717544.2020.1716876

Chen, C., Li, B., Cheng, G., Yang, X., Zhao, N., and Shi, R. (2018). Amentoflavone Ameliorates A $\beta 1$-42-Induced Memory Deficits and Oxidative Stress in Cellular and Rat Model. Neurochem. Res. 43 (4), 857-868. doi:10.1007/s11064-0182489-8 
Chen, C. C., Liu, H. P., Chao, M., Liang, Y., Tsang, N. M., Huang, H. Y., et al. (2014). NF-kB-mediated Transcriptional Upregulation of TNFAIP2 by the Epstein-Barr Virus Oncoprotein, LMP1, Promotes Cell Motility in Nasopharyngeal Carcinoma. Oncogene 33 (28), 3648-3659. doi:10.1038/ onc. 2013.345

Chen, C. H., Huang, Y. C., Lee, Y. H., Tan, Z. L., Tsai, C. J., Chuang, Y. C., et al. (2020b). Anticancer Efficacy and Mechanism of Amentoflavone for Sensitizing Oral Squamous Cell Carcinoma to Cisplatin. Anticancer Res. 40 (12), 6723-6732. doi:10.21873/anticanres.14695

Chen, G., Han, Y., He, W., and Liang, F. (2016). Amentoflavone Protects against High Fat-Induced Metabolic Dysfunction: Possible Role of the Regulation of Adipogenic Differentiation. Int. J. Mol. Med. 38 (6), 1759-1767. doi:10.3892/ ijmm.2016.2772

Chen, J. H., Chen, W. L., and Liu, Y. C. (2015). Amentoflavone Induces Antiangiogenic and Anti-metastatic Effects through Suppression of NF-Kb Activation in MCF-7 Cells. Anticancer Res. 35 (12), 6685-6693.

Chen, W. L., Hsieh, C. L., Chen, J. H., Huang, C. S., Chen, W. T., Kuo, Y. C., et al. (2017a). Amentoflavone Enhances Sorafenib-Induced Apoptosis through Extrinsic and Intrinsic Pathways in Sorafenib-Resistant Hepatocellular Carcinoma SK-Hep1 Cells In Vitro. Oncol. Lett. 14 (3), 3229-3234. doi:10.3892/ol.2017.6540

Chen, W. T., Chen, C. H., Su, H. T., Yueh, P. F., Hsu, F. T., and Chiang, I. T. (2021). Amentoflavone Induces Cell-Cycle Arrest, Apoptosis, and Invasion Inhibition in Non-small Cell Lung Cancer Cells. Anticancer Res. 41 (3), 1357-1364. doi:10.21873/anticanres.14893

Chen, Y., Hong, T., Wang, S., Mo, J., Tian, T., and Zhou, X. (2017b). Epigenetic Modification of Nucleic Acids: from Basic Studies to Medical Applications. Chem. Soc. Rev. 46 (10), 2844-2872. doi:10.1039/c6cs00599c

Chen, Y., Li, N., Wang, H., Wang, N., Peng, H., Wang, J., et al. (2020c). Amentoflavone Suppresses Cell Proliferation and Induces Cell Death through Triggering Autophagy-dependent Ferroptosis in Human Glioma. Life Sci. 247, 117425. doi:10.1016/j.lfs.2020.117425

Chiang, C. H., Yeh, C. Y., Chung, J. G., Chiang, I. T., and Hsu, F. T. (2019). Amentoflavone Induces Apoptosis and Reduces Expression of Anti-apoptotic and Metastasis-Associated Proteins in Bladder Cancer. Anticancer Res. 39 (7), 3641-3649. doi:10.21873/anticanres.13512

Cho, N. H., Shaw, J. E., Karuranga, S., Huang, Y., da Rocha Fernandes, J. D., Ohlrogge, A. W., et al. (2018). IDF Diabetes Atlas: Global Estimates of Diabetes Prevalence for 2017 and Projections for 2045. Diabetes Res. Clin. Pract. 138, 271-281. doi:10.1016/j.diabres.2018.02.023

Choi, E. Y., Kang, S. S., Lee, S. K., and Han, B. H. (2020). Polyphenolic Biflavonoids Inhibit Amyloid-Beta Fibrillation and Disaggregate Preformed Amyloid-Beta Fibrils. Biomol. Ther. (Seoul) 28 (2), 145-151. doi:10.4062/biomolther.2019.113

Cholbi, M. R., Paya, M., and Alcaraz, M. J. (1991). Inhibitory Effects of Phenolic Compounds on CCl4-Induced Microsomal Lipid Peroxidation. Experientia 47 (2), 195-199. doi:10.1007/BF01945426

Chung, J. H., Seo, J. Y., Choi, H. R., Lee, M. K., Youn, C. S., Rhie, G., et al. (2001). Modulation of Skin Collagen Metabolism in Aged and Photoaged Human Skin In Vivo. J. Invest Dermatol. 117 (5), 1218-1224. doi:10.1046/j.0022202x.2001.01544.x

Coulerie, P., Nour, M., Maciuk, A., Eydoux, C., Guillemot, J. C., Lebouvier, N., et al. (2013). Structure-activity Relationship Study of Biflavonoids on the Dengue Virus Polymerase DENV-NS5 RdRp. Planta Med. 79 (14), 1313-1318. doi:10.1055/s-0033-1350672

De Craene, B., and Berx, G. (2013). Regulatory Networks Defining EMT during Cancer Initiation and Progression. Nat. Rev. Cancer 13 (2), 97-110. doi:10.1038/nrc3447

de Lau, L. M., and Breteler, M. M. (2006). Epidemiology of Parkinson's Disease. Lancet Neurol. 5 (6), 525-535. doi:10.1016/S1474-4422(06)70471-9

De Vivo, M., Masetti, M., Bottegoni, G., and Cavalli, A. (2016). Role of Molecular Dynamics and Related Methods in Drug Discovery. J. Med. Chem. 59 (9), 4035-4061. doi:10.1021/acs.jmedchem.5b01684

Dell'Agli, M., Galli, G. V., and Bosisio, E. (2006). Inhibition of cGMPPhosphodiesterase-5 by Biflavones of Ginkgo Biloba. Planta Med. 72 (5), 468-470. doi:10.1055/s-2005-916236

Durcan, M. J., and Lister, R. G. (1989). Does Directed Exploration Influence Locomotor Activity in a Holeboard Test? Behav. Neural Biol. 51 (1), 121-125. doi:10.1016/s0163-1047(89)90751-6
Ellis, A. E. (2001). Innate Host Defense Mechanisms of Fish against Viruses and Bacteria. Dev. Comp. Immunol. 25 (8-9), 827-839. doi:10.1016/s0145-305x(01) 00038-6

Feng, X., Chen, Y., Li, L., Zhang, Y., Zhang, L., and Zhang, Z. (2020). Preparation, Evaluation and Metabolites Study in Rats of Novel Amentoflavone-Loaded TPGS/soluplus Mixed Nanomicelles. Drug Deliv. 27 (1), 137-150. doi:10.1080/ 10717544.2019.1709920

Fischer, U., Janssen, K., and Schulze-Osthoff, K. (2007). Cutting-edge ApoptosisBased Therapeutics: a Panacea for Cancer? BioDrugs 21 (5), 273-297. doi:10.2165/00063030-200721050-00001

Fittipaldi, N., Segura, M., Grenier, D., and Gottschalk, M. (2012). Virulence Factors Involved in the Pathogenesis of the Infection Caused by the Swine Pathogen and Zoonotic Agent Streptococcus Suis. Future Microbiol. 7 (2), 259-279. doi:10.2217/fmb.11.149

Ghosh, R., Chakraborty, A., Biswas, A., and Chowdhuri, S. (2020). Computer Aided Identification of Potential SARS CoV-2 Main Protease Inhibitors from Diterpenoids and Biflavonoids of Torreya Nucifera Leaves. J. Biomol. Struct. Dyn. 1, 1-16. doi:10.1080/07391102.2020.1841680

Guruvayoorappan, C., and Kuttan, G. (2008a). Amentoflavone Inhibits Experimental Tumor Metastasis through a Regulatory Mechanism Involving MMP-2, MMP-9, Prolyl Hydroxylase, Lysyl Oxidase, VEGF, ERK-1, ERK-2, STAT-1, NM23 and Cytokines in Lung Tissues of C57BL/6 Mice. Immunopharmacol Immunotoxicol 30 (4), 711-727. doi:10.1080/ 08923970802278276

Guruvayoorappan, C., and Kuttan, G. (2008b). Amentoflavone Stimulates Apoptosis in B16F-10 Melanoma Cells by Regulating Bcl-2, P53 as Well as Caspase-3 Genes and Regulates the Nitric Oxide as Well as Proinflammatory Cytokine Production in B16F-10 Melanoma Cells, Tumor Associated Macrophages and Peritoneal Macrophages. J. Exp. Ther. Oncol. 7 (3), 207-218.

Guruvayoorappan, C., and Kuttan, G. (2007). Effect of Amentoflavone on the Inhibition of Pulmonary Metastasis Induced by B16F-10 Melanoma Cells in C57BL/6 Mice. Integr. Cancer Ther. 6 (2), 185-197. doi:10.1177/ 1534735407302345

Guruvayoorappan, C., and Kuttan, G. (2008c). Inhibition of Tumor Specific Angiogenesis by Amentoflavone. Biochemistry (Mosc) 73 (2), 209-218. doi:10.1134/s0006297908020132

Haas, B., and Grenier, D. (2018). Understanding the Virulence of Streptococcus Suis: A Veterinary, Medical, and Economic challenge. Med. Mal Infect 48 (3), 159-166. doi:10.1016/j.medmal.2017.10.001

Hammer, K. D., Hillwig, M. L., Solco, A. K., Dixon, P. M., Delate, K., Murphy, P. A., et al. (2007). Inhibition of Prostaglandin E(2) Production by Anti-inflammatory hypericum Perforatum Extracts and Constituents in RAW264.7 Mouse Macrophage Cells. J. Agric. Food Chem. 55 (18), 7323-7331. doi:10.1021/ jf0710074

Hoy, D. G., Smith, E., Cross, M., Sanchez-Riera, L., Buchbinder, R., Blyth, F. M., et al. (2014). The Global burden of Musculoskeletal Conditions for 2010: an Overview of Methods. Ann. Rheum. Dis. 73 (6), 982-989. doi:10.1136/ annrheumdis-2013-204344

Hsu, F. T., Chiang, I. T., Kuo, Y. C., Hsia, T. C., Lin, C. C., Liu, Y. C., et al. (2019). Amentoflavone Effectively Blocked the Tumor Progression of Glioblastoma via Suppression of ERK/NF- $\kappa$ B Signaling Pathway. Am. J. Chin Med. 47 (4), 913-931. doi:10.1142/S0192415X19500484

Hu, X. L., Feng, J. H., Pham, T. A., Ma, H. Y., Ma, M. X., Song, R., et al. (2018). Identification of Amentoflavone as a Potent Highly Selective PARP-1 Inhibitor and its Potentiation on Carboplatin in Human Non-small Cell Lung Cancer. Phytomedicine 50, 88-98. doi:10.1016/j.phymed.2018.09.012

Huang, C., Wang, Y., Li, X., Ren, L., Zhao, J., Hu, Y., et al. (2020). Clinical Features of Patients Infected with 2019 Novel Coronavirus in Wuhan, China. Lancet 395 (10223), 497-506. doi:10.1016/S0140-6736(20)30183-5

Huang, N., Rizshsky, L., Hauck, C. C., Nikolau, B. J., Murphy, P. A., and Birt, D. F. (2012). The Inhibition of Lipopolysaccharide-Induced Macrophage Inflammation by 4 Compounds in Hypericum perforatum Extract Is Partially Dependent on the Activation of SOCS3. Phytochemistry 76, 106-116. doi:10.1016/j.phytochem.2011.12.001

Hwang, I. S., Lee, J., Jin, H. G., Woo, E. R., and Lee, D. G. (2012). Amentoflavone Stimulates Mitochondrial Dysfunction and Induces Apoptotic Cell Death in Candida Albicans. Mycopathologia 173 (4), 207-218. doi:10.1007/s11046-0119503-X 
Hwang, J. H., Choi, H., Woo, E. R., and Lee, D. G. (2013). Antibacterial Effect of Amentoflavone and its Synergistic Effect with Antibiotics. J. Microbiol. Biotechnol. 23 (7), 953-958. doi:10.4014/jmb.1302.02045

Igney, F. H., and Krammer, P. H. (2002). Death and Anti-death: Tumour Resistance to Apoptosis. Nat. Rev. Cancer 2 (4), 277-288. doi:10.1038/nrc776

Ishola, I. O., Chatterjee, M., Tota, S., Tadigopulla, N., Adeyemi, O. O., Palit, G., et al. (2012). Antidepressant and Anxiolytic Effects of Amentoflavone Isolated from Cnestis Ferruginea in Mice. Pharmacol. Biochem. Behav. 103 (2), 322-331. doi:10.1016/j.pbb.2012.08.017

Ishola, I. O., Chaturvedi, J. P., Rai, S., Rajasekar, N., Adeyemi, O. O., Shukla, R., et al. (2013). Evaluation of Amentoflavone Isolated from Cnestis Ferruginea Vahl Ex DC (Connaraceae) on Production of Inflammatory Mediators in LPS Stimulated Rat Astrocytoma Cell Line (C6) and THP-1 Cells. J. Ethnopharmacol 146 (2), 440-448. doi:10.1016/j.jep.2012.12.015

Jedrzejas, M. J. (2001). Pneumococcal Virulence Factors: Structure and Function. Microbiol. Mol. Biol. Rev. 65 (2), 187. doi:10.1128/MMBR.65.2.187-207.2001

Jenkins, G. (2002). Molecular Mechanisms of Skin Ageing. Mech. Ageing Dev. 123 (7), 801-810. doi:10.1016/s0047-6374(01)00425-0

Jeong, E. J., Seo, H., Yang, H., Kim, J., Sung, S. H., and Kim, Y. C. (2012). Antiinflammatory Phenolics Isolated from Juniperus Rigida Leaves and Twigs in Lipopolysaccharide-Stimulated RAW264.7 Macrophage Cells. J. Enzyme Inhib. Med. Chem. 27 (6), 875-879. doi:10.3109/14756366.2011.625025

Jewell, J. L., Russell, R. C., and Guan, K. L. (2013). Amino Acid Signalling Upstream of mTOR. Nat. Rev. Mol. Cell Biol 14 (3), 133-139. doi:10.1038/nrm3522

Jou, J., and Diehl, A. M. (2010). Epithelial-mesenchymal Transitions and Hepatocarcinogenesis. J. Clin. Invest 120 (4), 1031-1034. doi:10.1172/JCI42615

Jung, H. J., Park, K., Lee, I. S., Kim, H. S., Yeo, S. H., Woo, E. R., et al. (2007). S-phase Accumulation of Candida Albicans by Anticandidal Effect of Amentoflavone Isolated from Selaginella Tamariscina. Biol. Pharm. Bull 30 (10), 1969-1971. doi:10.1248/bpb.30.1969

Jung, H. J., Sung, W. S., Yeo, S. H., Kim, H. S., Lee, I. S., Woo, E. R., et al. (2006). Antifungal Effect of Amentoflavone Derived from Selaginella Tamariscina. Arch. Pharm. Res. 29 (9), 746-751. doi:10.1007/BF02974074

Jung, Y. J., Lee, E. H., Lee, C. G., Rhee, K. J., Jung, W. S., Choi, Y., et al. (2017). AKR1B10-inhibitory Selaginella Tamariscina Extract and Amentoflavone Decrease the Growth of A549 Human Lung Cancer Cells In Vitro and In Vivo. J. Ethnopharmacol 202, 78-84. doi:10.1016/j.jep.2017.03.010

Jürgenliemk, G., and Nahrstedt, A. (2002). Phenolic Compounds from Hypericum perforatum. Planta Med. 68 (1), 88-91. doi:10.1055/s-2002-20053

Kadam, R. U., Garg, D., Paul, A. T., Bhutani, K. K., and Roy, N. (2007). Evaluation of Proinflammatory Cytokine Pathway Inhibitors for P38 MAPK Inhibitory Potential. J. Med. Chem. 50 (25), 6337-6342. doi:10.1021/jm0706923

Kalluri, R., and Weinberg, R. A. (2009). The Basics of Epithelial-Mesenchymal Transition. J. Clin. Invest 119 (6), 1420-1428. doi:10.1172/JCI39104

Kang, D. G., Yin, M. H., Oh, H., Lee, D. H., and Lee, H. S. (2004). Vasorelaxation by Amentoflavone Isolated from Selaginella Tamariscina. Planta Med. 70 (8), 718-722. doi:10.1055/s-2004-827201

Kang, S. S., Lee, J. Y., Choi, Y. K., Song, S. S., Kim, J. S., Jeon, S. J., et al. (2005). Neuroprotective Effects of Naturally Occurring Biflavonoids. Bioorg. Med. Chem. Lett. 15 (15), 3588-3591. doi:10.1016/j.bmcl.2005.05.078

Kaplanski, G., Marin, V., Montero-Julian, F., Mantovani, A., and Farnarier, C. (2003). IL-6: a Regulator of the Transition from Neutrophil to Monocyte Recruitment during Inflammation. Trends Immunol. 24 (1), 25-29. doi:10.1016/s1471-4906(02)00013-3

Kim, G. L., Jang, E. H., Lee, D. E., Bang, C., Kang, H., Kim, S., et al. (2020). Amentoflavone, Active Compound of Selaginella Tamariscina, Inhibits In Vitro and In Vivo TGF- $\beta$-Induced Metastasis of Human Cancer Cells. Arch. Biochem. Biophys. 687, 108384. doi:10.1016/j.abb.2020.108384

Kim, H. K., Son, K. H., Chang, H. W., Kang, S. S., and Kim, H. P. (1998). Amentoflavone, a Plant Biflavone: a New Potential Anti-inflammatory Agent. Arch. Pharm. Res. 21 (4), 406-410. doi:10.1007/BF02974634

Kimura, Y., Ito, H., Ohnishi, R., and Hatano, T. (2010). Inhibitory Effects of Polyphenols on Human Cytochrome P450 3A4 and 2C9 Activity. Food Chem. Toxicol. 48 (1), 429-435. doi:10.1016/j.fct.2009.10.041

Kirtipal, N., Bharadwaj, S., and Kang, S. G. (2020). From SARS to SARS-CoV-2, Insights on Structure, Pathogenicity and Immunity Aspects of Pandemic Human Coronaviruses. Infect Genet. Evol. 85, 104502. doi:10.1016/ j.meegid.2020.104502
Kligman, L. H. (1989). The Ultraviolet-Irradiated Hairless Mouse: a Model for Photoaging. J. Am. Acad. Dermatol. 21 (3 Pt 2), 623-631. doi:10.1016/s01909622(89)70229-2

Krauze-Baranowska, M., Cisowski, W., Wiwart, M., and Madziar, B. (1999). Antifungal Biflavones from Cupressocyparis Leylandii. Planta Med. 65 (6), 572-573. doi:10.1055/s-2006-960828

Kumar, A., Choudhir, G., Shukla, S. K., Sharma, M., Tyagi, P., Bhushan, A., et al. (2021). Identification of Phytochemical Inhibitors against Main Protease of COVID-19 Using Molecular Modeling Approaches. J. Biomol. Struct. Dyn. 39 (10), 3760-3770. doi:10.1080/07391102.2020.1772112

Kumar, S., Sahu, P., and Jena, L. (2019). An In Silico Approach to Identify Potential Inhibitors against Multiple Drug Targets of Mycobacterium tuberculosis. Int. J. Mycobacteriol 8 (3), 252-261. doi:10.4103/ijmy.ijmy_109_19

Kuo, G., Choo, Q. L., Alter, H. J., Gitnick, G. L., Redeker, A. G., Purcell, R. H., et al. (1989). An Assay for Circulating Antibodies to a Major Etiologic Virus of Human Non-A, Non-B Hepatitis. Science 244 (4902), 362-364. doi:10.1126/ science. 2496467

Kuo, Y. H., Yeh, Y. T., Pan, S. Y., and Hsieh, S. C. (2019). Identification and Structural Elucidation of Anti-inflammatory Compounds from Chinese Olive (Canarium Album L.) Fruit Extracts. Foods 8 (10). doi:10.3390/foods8100441

Lai, C. C., Shih, T. P., Ko, W. C., Tang, H. J., and Hsueh, P. R. (2020). Severe Acute Respiratory Syndrome Coronavirus 2 (SARS-CoV-2) and Coronavirus Disease2019 (COVID-19): The Epidemic and the Challenges. Int. J. Antimicrob. Agents 55 (3), 105924. doi:10.1016/j.ijantimicag.2020.105924

Lee, C. W., Choi, H. J., Kim, H. S., Kim, D. H., Chang, I. S., Moon, H. T., et al. (2008). Biflavonoids Isolated from Selaginella Tamariscina Regulate the Expression of Matrix Metalloproteinase in Human Skin Fibroblasts. Bioorg. Med. Chem. 16 (2), 732-738. doi:10.1016/j.bmc.2007.10.036

Lee, C. W., Na, Y., Park, N. H., Kim, H. S., Ahn, S. M., Kim, J. W., et al. (2012). Amentoflavone Inhibits UVB-Induced Matrix Metalloproteinase-1 Expression through the Modulation of AP-1 Components in normal Human Fibroblasts. Appl. Biochem. Biotechnol. 166 (5), 1137-1147. doi:10.1007/s12010-011-9500-z

Lee, D. M., and Weinblatt, M. E. (2001). Rheumatoid Arthritis. Lancet 358 (9285), 903-911. doi:10.1016/S0140-6736(01)06075-5

Lee, H. S., Oh, W. K., Kim, B. Y., Ahn, S. C., Kang, D. O., Shin, D. I., et al. (1996). Inhibition of Phospholipase C Gamma 1 Activity by Amentoflavone Isolated from Selaginella Tamariscina. Planta Med. 62 (4), 293-296. doi:10.1055/s-2006957887

Lee, J., Kim, M., Jeong, S. E., Park, H. Y., Jeon, C. O., and Park, W. (2020). Amentoflavone, a Novel Cyanobacterial Killing Agent from Selaginella Tamariscina. J. Hazard Mater. 384, 121312. doi:10.1016/j.jhazmat.2019.121312

Lee, J. C., Laydon, J. T., McDonnell, P. C., Gallagher, T. F., Kumar, S., Green, D., et al. (1994). A Protein Kinase Involved in the Regulation of Inflammatory Cytokine Biosynthesis. Nature 372 (6508), 739-746. doi:10.1038/372739a0

Lee, J. S., Lee, M. S., Oh, W. K., and Sul, J. Y. (2009). Fatty Acid Synthase Inhibition by Amentoflavone Induces Apoptosis and Antiproliferation in Human Breast Cancer Cells. Biol. Pharm. Bull 32 (8), 1427-1432. doi:10.1248/bpb.32.1427

Lee, J. S., Sul, J. Y., Park, J. B., Lee, M. S., Cha, E. Y., Song, I. S., et al. (2013). Fatty Acid Synthase Inhibition by Amentoflavone Suppresses HER2/neu (erbB2) Oncogene in SKBR3 Human Breast Cancer Cells. Phytother Res. 27 (5), 713-720. doi:10.1002/ptr.4778

Lee, K. C., Chen, W. T., Liu, Y. C., Lin, S. S., and Hsu, F. T. (2018a). Amentoflavone Inhibits Hepatocellular Carcinoma Progression through Blockage of ERK/NFKB Activation. In Vivo 32 (5), 1097-1103. doi:10.21873/invivo.11351

Lee, K. C., Tsai, J. J., Tseng, C. W., Kuo, Y. C., Chuang, Y. C., Lin, S. S., et al. (2018b). Amentoflavone Inhibits ERK-Modulated Tumor Progression in Hepatocellular Carcinoma In Vitro. In Vivo 32 (3), 549-554. doi:10.21873/invivo.11274

Lee, M. K., Lim, S. W., Yang, H., Sung, S. H., Lee, H. S., Park, M. J., et al. (2006). Osteoblast Differentiation Stimulating Activity of Biflavonoids from Cephalotaxus Koreana. Bioorg. Med. Chem. Lett. 16 (11), 2850-2854. doi:10.1016/j.bmcl.2006.03.018

Lee, S., Kim, H., Kang, J. W., Kim, J. H., Lee, D. H., Kim, M. S., et al. (2011). The Biflavonoid Amentoflavone Induces Apoptosis via Suppressing E7 Expression, Cell Cycle Arrest at Sub- $G_{1}$ Phase, and Mitochondria-Emanated Intrinsic Pathways in Human Cervical Cancer Cells. J. Med. Food 14 (7-8), 808-816. doi:10.1089/jmf.2010.1428

Lee, W. P., Lan, K. L., Liao, S. X., Huang, Y. H., Hou, M. C., and Lan, K. H. (2018c). Inhibitory Effects of Amentoflavone and Orobol on Daclatasvir-Induced 
Resistance-Associated Variants of Hepatitis C Virus. Am. J. Chin Med. 46 (4), 835-852. doi:10.1142/S0192415X18500441

Lee, Y. J., Chung, J. G., Chien, Y. T., Lin, S. S., and Hsu, F. T. (2019). Suppression of ERK/NF- $\kappa B$ Activation Is Associated with Amentoflavone-Inhibited Osteosarcoma Progression In Vivo. Anticancer Res. 39 (7), 3669-3675. doi:10.21873/anticanres.13515

Lewis, R., Gómez Álvarez, C. B., Rayman, M., Lanham-New, S., Woolf, A., and Mobasheri, A. (2019). Strategies for Optimising Musculoskeletal Health in the 21st century. BMC Musculoskelet. Disord. 20 (1), 164. doi:10.1186/s12891-0192510-7

Li, F., Song, X., Su, G., Wang, Y., Wang, Z., Jia, J., et al. (2019a). Amentoflavone Inhibits HSV-1 and ACV-Resistant Strain Infection by Suppressing Viral Early Infection. Viruses 11 (5), 1. doi:10.3390/v11050466

Li, F. (2016). Structure, Function, and Evolution of Coronavirus Spike Proteins. Annu. Rev. Virol. 3 (1), 237-261. doi:10.1146/annurev-virology-110615-042301

Li, M., Li, B., Hou, Y., Tian, Y., Chen, L., Liu, S., et al. (2019b). Anti-inflammatory Effects of Chemical Components from Ginkgo Biloba L. Male Flowers on Lipopolysaccharide-Stimulated RAW264.7 Macrophages. Phytother Res. 33 (4), 989-997. doi:10.1002/ptr.6292

Li, Y. L., Chen, X., Niu, S. Q., Zhou, H. Y., and Li, Q. S. (2020). Protective Antioxidant Effects of Amentoflavone and Total Flavonoids from Hedyotis Diffusa on $\mathrm{H} 2 \mathrm{O} 2$-Induced HL-O2 Cells through ASK1/p38 MAPK Pathway. Chem. Biodivers 17 (7), e2000251. doi:10.1002/cbdv.202000251

Lin, Y. M., Anderson, H., Flavin, M. T., Pai, Y. H., Mata-Greenwood, E., Pengsuparp, T., et al. (1997). In Vitro anti-HIV Activity of Biflavonoids Isolated from Rhus Succedanea and Garcinia Multiflora. J. Nat. Prod. 60 (9), 884-888. doi:10.1021/np9700275

Liu, H., Yue, Q., and He, S. (2017a). Amentoflavone Suppresses Tumor Growth in Ovarian Cancer by Modulating Skp2. Life Sci. 189, 96-105. doi:10.1016/j.lfs.2017.09.026

Liu, S., Yang, X., Zhang, H., Zhang, J., Zhou, Y., Wang, T., et al. (2020a). Amentoflavone Attenuates Clostridium perfringens Gas Gangrene by Targeting Alpha-Toxin and Perfringolysin O. Front Pharmacol. 11, 179. doi:10.3389/fphar.2020.00179

Liu, Y. C., Wu, R. H., and Wang, W. S. (2017b). Regorafenib Diminishes the Expression and Secretion of Angiogenesis and Metastasis Associated Proteins and Inhibits Cell Invasion via NF-Kb Inactivation in SK-Hep1 Cells. Oncol. Lett. 14 (1), 461-467. doi:10.3892/ol.2017.6142

Liu, Z., Wang, F., Ma, H., Xia, H., Tian, J., and Sun, T. (2020b). Amentoflavone Induces Cell Cycle Arrest, Apoptosis, and Autophagy in BV-2 Cells. Front Biosci. (Landmark Ed. 25, 798-816. doi:10.2741/4835

Lobstein-Guth, A., Briançon-Scheid, F., Victoire, C., Haag-Berrurier, M., and Anton, R. (1988). Isolation of Amentoflavone from Ginkgo Biloba. Planta Med. 54 (6), 555-556. doi:10.1055/s-2006-962549

Lokhande, K., Nawani, N., K Venkateswara, S., and Pawar, S. (2020). Biflavonoids from Rhus Succedanea as Probable Natural Inhibitors against SARS-CoV-2: a Molecular Docking and Molecular Dynamics Approach. J. Biomol. Struct. Dyn. 1, 1-13. doi:10.1080/07391102.2020.1858165

Lv, X., Zhang, J. B., Wang, X. X., Hu, W. Z., Shi, Y. S., Liu, S. W., et al. (2018). Amentoflavone Is a Potent Broad-Spectrum Inhibitor of Human UDPGlucuronosyltransferases. Chem. Biol. Interact 284, 48-55. doi:10.1016/ j.cbi.2018.02.009

Ma, D. L., Chan, D. S., Wei, G., Zhong, H. J., Yang, H., Leung, L. T., et al. (2014). Virtual Screening and Optimization of Type II Inhibitors of JAK2 from a Natural Product Library. Chem. Commun. (Camb) 50 (90), 13885-13888. doi: $10.1039 / \mathrm{c} 4 \mathrm{cc} 04498 \mathrm{c}$

Ma, S. C., But, P. P., Ooi, V. E., He, Y. H., Lee, S. H., Lee, S. F., et al. (2001). Antiviral Amentoflavone from Selaginella Sinensis. Biol. Pharm. Bull 24 (3), 311-312. doi:10.1248/bpb.24.311

Marinho, M. M., Almeida-Neto, F. W. Q., Marinho, E. M., da Silva, L. P., Menezes, R. R. P. P. B., Dos Santos, R. P., et al. (2021). Quantum Computational Investigations and Molecular Docking Studies on Amentoflavone. Heliyon 7 (1), e06079. doi:10.1016/j.heliyon.2021.e06079

Massé, N., Davidson, A., Ferron, F., Alvarez, K., Jacobs, M., Romette, J. L., et al. (2010). Dengue Virus Replicons: Production of an Interserotypic Chimera and Cell Lines from Different Species, and Establishment of a Cell-Based Fluorescent Assay to Screen Inhibitors, Validated by the Evaluation of Ribavirin's Activity. Antivir. Res 86 (3), 296-305. doi:10.1016/ j.antiviral.2010.03.010
Mathew, R., Karantza-Wadsworth, V., and White, E. (2007). Role of Autophagy in Cancer. Nat. Rev. Cancer 7 (12), 961-967. doi:10.1038/nrc2254

Miroshnychenko, K. V., and Shestopalova, A. V. (2021). Combined Use of the Hepatitis C Drugs and Amentoflavone Could Interfere with Binding of the Spike Glycoprotein of SARS-CoV-2 to ACE2: the Results of a Molecular Simulation Study. J. Biomol. Struct. Dyn. 1, 1-15. doi:10.1080/07391102.2021.1914168

Na, M., Kim, K. A., Oh, H., Kim, B. Y., Oh, W. K., and Ahn, J. S. (2007). Protein Tyrosine Phosphatase 1B Inhibitory Activity of Amentoflavone and its Cellular Effect on Tyrosine Phosphorylation of Insulin Receptors. Biol. Pharm. Bull 30 (2), 379-381. doi:10.1248/bpb.30.379

Nayak, T., Jena, L., Waghmare, P., and Harinath, B. C. (2018). Identification of Potential Inhibitors for Mycobacterial Uridine DiphosphogalactofuranoseGalactopyranose Mutase Enzyme: A Novel Drug Target through In Silico Approach. Int. J. Mycobacteriol 7 (1), 61-68. doi:10.4103/ijmy.ijmy_174_17

Oh, J., Rho, H. S., Yang, Y., Yoon, J. Y., Lee, J., Hong, Y. D., et al. (2013). Extracellular Signal-Regulated Kinase Is a Direct Target of the Antiinflammatory Compound Amentoflavone Derived from Torreya Nucifera. Mediators Inflamm. 2013, 761506. doi:10.1155/2013/761506

Okigawa, M., Hwa, C. W., Kawano, N., and Rahman, W. (1971). Biflavones in Selaginella Species. Phytochemistry 10 (12), 3286-3287. doi:10.1016/s00319422(00)97392-8

Pan, P. J., Tsai, J. J., and Liu, Y. C. (2017). Amentoflavone Inhibits Metastatic Potential through Suppression of ERK/NF- $\mathrm{kB}$ Activation in Osteosarcoma U2OS Cells. Anticancer Res. 37 (9), 4911-4918. doi:10.21873/anticanres.11900

Pan, X., Tan, N., Zeng, G., Zhang, Y., and Jia, R. (2005). Amentoflavone and its Derivatives as Novel Natural Inhibitors of Human Cathepsin B. Bioorg. Med. Chem. 13 (20), 5819-5825. doi:10.1016/j.bmc.2005.05.071

Park, H. J., and Kim, M. M. (2019). Amentoflavone Induces Autophagy and Modulates P53. Cell J 21 (1), 27-34. doi:10.22074/cellj.2019.5717

Park, N. H., Lee, C. W., Bae, J. H., and Na, Y. J. (2011). Protective Effects of Amentoflavone on Lamin A-dependent UVB-Induced Nuclear Aberration in normal Human Fibroblasts. Bioorg. Med. Chem. Lett. 21 (21), 6482-6484. doi:10.1016/j.bmcl.2011.08.067

Park, S. Y., Nguyen, P. H., Kim, G., Jang, S. N., Lee, G. H., Phuc, N. M., et al. (2020). Strong and Selective Inhibitory Effects of the Biflavonoid Selamariscina A against CYP2C8 and CYP2C9 Enzyme Activities in Human Liver Microsomes. Pharmaceutics 12 (4), 1. doi:10.3390/pharmaceutics 12040343

Patil, R., Chikhale, R., Khanal, P., Gurav, N., Ayyanar, M., Sinha, S., et al. (2021). Computational and Network Pharmacology Analysis of Bioflavonoids as Possible Natural Antiviral Compounds in COVID-19. Inform Med. Unlocked 22, 100504. doi:10.1016/j.imu.2020.100504

Pei, J. S., Liu, C. C., Hsu, Y. N., Lin, L. L., Wang, S. C., Chung, J. G., et al. (2012). Amentoflavone Induces Cell-Cycle Arrest and Apoptosis in MCF-7 Human Breast Cancer Cells via Mitochondria-dependent Pathway. In Vivo 26 (6), 963-970.

Pham-Huy, L. A., He, H., and Pham-Huy, C. (2008). Free Radicals, Antioxidants in Disease and Health. Int. J. Biomed. Sci. 4 (2), 89-96.

Puttaswamy, H., Gowtham, H. G., Ojha, M. D., Yadav, A., Choudhir, G., Raguraman, V., et al. (2020). In Silico studies Evidenced the Role of Structurally Diverse Plant Secondary Metabolites in Reducing SARS-CoV-2 Pathogenesis. Sci. Rep. 10 (1), 20584. doi:10.1038/s41598-020-77602-0

Qiao, Y., Liu, X., Li, X., Wang, X., Li, C., Khutsishvili, M., et al. (2019). Biflavonoids from Juniperus Oblonga Inhibit Organic Anion Transporter 3. Biochem. Biophys. Res. Commun. 509 (4), 931-936. doi:10.1016/j.bbrc.2019.01.039

Qin, L., Zhao, Y., Zhang, B., and Li, Y. (2018). Amentoflavone Improves Cardiovascular Dysfunction and Metabolic Abnormalities in High Fructose and Fat Diet-Fed Rats. Food Funct. 9 (1), 243-252. doi:10.1039/c7fo01095h

Qu, X., Li, Q., Zhang, X., Wang, Z., Wang, S., and Zhou, Z. (2019). Amentoflavone Protects the Hematopoietic System of Mice against $\gamma$-irradiation. Arch. Pharm. Res. 42 (11), 1021-1029. doi:10.1007/s12272-019-01187-0

Rameshkumar, M. R., Indu, P., Arunagirinathan, N., Venkatadri, B., El-Serehy, H. A., and Ahmad, A. (2021). Computational Selection of Flavonoid Compounds as Inhibitors against SARS-CoV-2 Main Protease, RNA-dependent RNA Polymerase and Spike Proteins: A Molecular Docking Study. Saudi J. Biol. Sci. 28 (1), 448-458. doi:10.1016/j.sjbs.2020.10.028

Rasmi, R. R., Sakthivel, K. M., and Guruvayoorappan, C. (2020). NF-кB Inhibitors in Treatment and Prevention of Lung Cancer. Biomed. Pharmacother. 130, 110569. doi:10.1016/j.biopha.2020.110569 
Rittié, L., and Fisher, G. J. (2002). UV-light-induced Signal Cascades and Skin Aging. Ageing Res. Rev. 1 (4), 705-720. doi:10.1016/s1568-1637(02)00024-7

Rizk, Y. S., Fischer, A., Cunha, Mde. C., Rodrigues, P. O., Marques, M. C., Matos, Mde. F., et al. (2014). In Vitro activity of the Hydroethanolic Extract and Biflavonoids Isolated from Selaginella Sellowii on Leishmania (Leishmania) Amazonensis. Mem. Inst. Oswaldo Cruz 109 (8), 1050-1056. doi:10.1590/00740276140312

Rizk, Y. S., Santos-Pereira, S., Gervazoni, L., Hardoim, D. J., Cardoso, F. O., de Souza, C. D. S. F., et al. (2021). Amentoflavone as an Ally in the Treatment of Cutaneous Leishmaniasis: Analysis of its Antioxidant/Prooxidant Mechanisms. Front Cell Infect Microbiol 11, 615814. doi:10.3389/fcimb.2021.615814

Robinson, W. H., Lepus, C. M., Wang, Q., Raghu, H., Mao, R., Lindstrom, T. M., et al. (2016). Low-grade Inflammation as a Key Mediator of the Pathogenesis of Osteoarthritis. Nat. Rev. Rheumatol. 12 (10), 580-592. doi:10.1038/ nrrheum.2016.136

Rong, S., Wan, D., Fan, Y., Liu, S., Sun, K., Huo, J., et al. (2019). Amentoflavone Affects Epileptogenesis and Exerts Neuroprotective Effects by Inhibiting NLRP3 Inflammasome. Front Pharmacol. 10, 856. doi:10.3389/fphar.2019.00856

Ryu, Y. B., Jeong, H. J., Kim, J. H., Kim, Y. M., Park, J. Y., Kim, D., et al. (2010). Biflavonoids from Torreya Nucifera Displaying SARS-CoV 3CL(pro) Inhibition. Bioorg. Med. Chem. 18 (22), 7940-7947. doi:10.1016/ j.bmc. 2010.09 .035

Sabiiti, W., and consortium, T. (2017). Beyond the Numbers: Interpreting WHO's Global Tuberculosis Report 2016 to Inform TB Policy and Practice in the East African Community. East Afr. Health Res. J. 1 (1), 2-7. doi:10.24248/EAHRJ-D16-00364

Sabogal-Guáqueta, A. M., Carrillo-Hormaza, L., Osorio, E., and Cardona-Gómez, G. P. (2018). Effects of Biflavonoids from Garcinia Madruno on a Triple Transgenic Mouse Model of Alzheimer's Disease. Pharmacol. Res. 129, 128-138. doi:10.1016/j.phrs.2017.12.002

Sakthivel, K. M., and Guruvayoorappan, C. (2013). Amentoflavone Inhibits iNOS, COX-2 Expression and Modulates Cytokine Profile, NF-Kb Signal Transduction Pathways in Rats with Ulcerative Colitis. Int. Immunopharmacol 17 (3), 907-916. doi:10.1016/j.intimp.2013.09.022

Saponara, R., and Bosisio, E. (1998). Inhibition of cAMP-Phosphodiesterase by Biflavones of Ginkgo Biloba in Rat Adipose Tissue. J. Nat. Prod. 61 (11), 1386-1387. doi:10.1021/np970569m

Saravanan, K. M., Zhang, H., Senthil, R., Vijayakumar, K. K., Sounderrajan, V., Wei, Y., et al. (2020). Structural Basis for the Inhibition of SARS-CoV2 Main Protease by Indian Medicinal Plant-Derived Antiviral Compounds. J. Biomol. Struct. Dyn. 1, 1-9. doi:10.1080/07391102.2020.1834457

Sasaki, H., Kitoh, Y., Tsukada, M., Miki, K., Koyama, K., Juliawaty, L. D., et al. (2015). Inhibitory Activities of Biflavonoids against Amyloid- $\beta$ Peptide 42 Cytotoxicity in PC-12 Cells. Bioorg. Med. Chem. Lett. 25 (14), 2831-2833. doi:10.1016/j.bmcl.2015.04.106

Sasaki, H., Miki, K., Kinoshita, K., Koyama, K., Juliawaty, L. D., Achmad, S. A., et al. (2010). Beta-Secretase (BACE-1) Inhibitory Effect of Biflavonoids. Bioorg. Med. Chem. Lett. 20 (15), 4558-4560. doi:10.1016/j.bmcl.2010.06.021

Schieber, M., and Chandel, N. S. (2014). ROS Function in Redox Signaling and Oxidative Stress. Curr. Biol. 24 (10), R453-R462. doi:10.1016/j.cub.2014.03.034

Shen, F., Chen, Y., Chen, L., Qin, J., Li, Z., and Xu, J. (2019). Amentoflavone Promotes Apoptosis in Non-small-cell Lung Cancer by Modulating Cancerous Inhibitor of PP2A. Anat. Rec. (Hoboken) 302 (12), 2201-2210. doi:10.1002/ ar. 24229

Shen, X., Niu, X., Li, G., Deng, X., and Wang, J. (2018). Amentoflavone Ameliorates Streptococcus Suis-Induced Infection In Vitro and In Vivo. Appl. Environ. Microbiol. 84 (24). doi:10.1128/AEM.01804-18

Shin, D. H., Bae, Y. C., Kim-Han, J. S., Lee, J. H., Choi, I. Y., Son, K. H., et al. (2006). Polyphenol Amentoflavone Affords Neuroprotection against Neonatal Hypoxic-Ischemic Brain Damage via Multiple Mechanisms. J. Neurochem. 96 (2), 561-572. doi:10.1111/j.1471-4159.2005.03582.x

Siveen, K. S., and Kuttan, G. (2011). Effect of Amentoflavone, a Phenolic Component from Biophytum Sensitivum, on Cell Cycling and Apoptosis of B16F-10 Melanoma Cells. J. Environ. Pathol. Toxicol. Oncol. 30 (4), 301-309. doi:10.1615/jenvironpatholtoxicoloncol.v30.i4.30

Steru, L., Chermat, R., Thierry, B., and Simon, P. (1985). The Tail Suspension Test: a New Method for Screening Antidepressants in Mice. Psychopharmacology (Berl) 85 (3), 367-370. doi:10.1007/BF00428203
Su, C., Yang, C., Gong, M., Ke, Y., Yuan, P., Wang, X., et al. (2019). Antidiabetic Activity and Potential Mechanism of Amentoflavone in Diabetic Mice. Molecules 24 (11), 1. doi:10.3390/molecules24112184

Sun, L., Sharma, A. K., Han, B. H., and Mirica, L. M. (2020). Amentoflavone: A Bifunctional Metal Chelator that Controls the Formation of Neurotoxic Soluble A 442 Oligomers. ACS Chem. Neurosci. 11 (17), 2741-2752. doi:10.1021/ acschemneuro.0c00376

Swargiary, A., Mahmud, S., and Saleh, M. A. (2020). Screening of Phytochemicals as Potent Inhibitor of 3-chymotrypsin and Papain-like Proteases of SARSCoV2: an In Silico Approach to Combat COVID-19. J. Biomol. Struct. Dyn. 1, 1-15. doi:10.1080/07391102.2020.1835729

Tarallo, V., Lepore, L., Marcellini, M., Dal Piaz, F., Tudisco, L., Ponticelli, S., et al. (2011). The Biflavonoid Amentoflavone Inhibits Neovascularization Preventing the Activity of Proangiogenic Vascular Endothelial Growth Factors. J. Biol. Chem. 286 (22), 19641-19651. doi:10.1074/jbc.M110.186239

Taylor, R. C., Cullen, S. P., and Martin, S. J. (2008). Apoptosis: Controlled Demolition at the Cellular Level. Nat. Rev. Mol. Cell Biol 9 (3), 231-241. doi:10.1038/nrm 2312

Tian, X. G., Yan, J. K., Sun, C. P., Li, J. X., Ning, J., Wang, C., et al. (2021). Amentoflavone from Selaginella Tamariscina as a Potent Inhibitor of Gut Bacterial $\beta$-glucuronidase: Inhibition Kinetics and Molecular Dynamics Stimulation. Chem. Biol. Interact 340, 109453. doi:10.1016/j.cbi.2021.109453

Tordera, M., Ferrándiz, M. L., and Alcaraz, M. J. (1994). Influence of Antiinflammatory Flavonoids on Degranulation and Arachidonic Acid Release in Rat Neutrophils. Z. Naturforsch C J. Biosci. 49 (3-4), 235-240. doi:10.1515/znc-1994-3-412

Tørris, C., Molin, M., and Cvancarova Småstuen, M. (2014). Fish Consumption and its Possible Preventive Role on the Development and Prevalence of Metabolic Syndrome - a Systematic Review. Diabetol. Metab. Syndr. 6 (1), 112. doi:10.1186/1758-5996-6-112

Trang, D. T., Huyen, L. T., Nhiem, N. X., Quang, T. H., Hang, D. T. T., Yen, P. H., et al. (2016). Tirucallane Glycoside from the Leaves of Antidesma bunius and Inhibitory NO Production in BV2 Cells and RAW264.7 Macrophages. Nat. Prod. Commun. 11 (7), 935-937. doi:10.1177/1934578x1601100717

Tsai, J. J., Hsu, F. T., Pan, P. J., Chen, C. W., and Kuo, Y. C. (2018). Amentoflavone Enhances the Therapeutic Efficacy of Sorafenib by Inhibiting Anti-apoptotic Potential and Potentiating Apoptosis in Hepatocellular Carcinoma In Vivo. Anticancer Res. 38 (4), 2119-2125. doi:10.21873/anticanres.12452

Tsai, S. C., Liang, Y. H., Chiang, J. H., Liu, F. C., Lin, W. H., Chang, S. J., et al. (2012). Anti-inflammatory Effects of Calophyllum inophyllum L. In RAW264.7 Cells. Oncol. Rep. 28 (3), 1096-1102. doi:10.3892/or.2012.1873

Vasan, N., Baselga, J., and Hyman, D. M. (2019). A View on Drug Resistance in Cancer. Nature 575 (7782), 299-309. doi:10.1038/s41586-019-1730-1

Vasconcelos, C. C., Lopes, A. J. O., Sousa, E. L. F., Camelo, D. S., Lima, F. C. V. M., Rocha, C. Q. D., et al. (2019). Effects of Extract of Arrabidaea Chica Verlot on an Experimental Model of Osteoarthritis. Int. J. Mol. Sci. 20 (19), 1. doi:10.3390/ ijms 20194717

von Moltke, L. L., Weemhoff, J. L., Bedir, E., Khan, I. A., Harmatz, J. S., Goldman, P., et al. (2004). Inhibition of Human Cytochromes P450 by Components of Ginkgo Biloba. J. Pharm. Pharmacol. 56 (8), 1039-1044. doi:10.1211/ 0022357044021

Wahyudi, L. D., Jeong, J., Yang, H., and Kim, J. H. (2018). Amentoflavone-induced Oxidative Stress Activates NF-E2-Related Factor 2 via the P38 MAP KinaseAKT Pathway in Human Keratinocytes. Int. J. Biochem. Cell Biol 99, 100-108. doi:10.1016/j.biocel.2018.04.006

Wang, G., and Zhu, W. (2016). Molecular Docking for Drug Discovery and Development: a Widely Used Approach but Far from Perfect. Future Med. Chem. 8 (14), 1707-1710. doi:10.4155/fmc-2016-0143

Wang, H., Wang, Q., Yang, M., Yang, L., Wang, W., Ding, H., et al. (2018). Histomorphology and Innate Immunity during the Progression of Osteoarthritis: Does Synovitis Affect Cartilage Degradation? J. Cell Physiol 233 (2), 1342-1358. doi:10.1002/jcp.26011

Wang, M. Y., Zhao, R., Gao, L. J., Gao, X. F., Wang, D. P., and Cao, J. M. (2020). SARS-CoV-2: Structure, Biology, and Structure-Based Therapeutics Development. Front Cell Infect Microbiol 10, 587269. doi:10.3389/ fcimb. 2020.587269

Wang, R., and Wang, G. (2019). Protein Modification and Autophagy Activation. Adv. Exp. Med. Biol. 1206, 237-259. doi:10.1007/978-981-15-0602-4_12 
Wei, T. Z., Wang, H., Wu, X. Q., Lu, Y., Guan, S. H., Dong, F. Q., et al. (2020). In Silico Screening of Potential Spike Glycoprotein Inhibitors of SARS-CoV-2 with Drug Repurposing Strategy. Chin J. Integr. Med. 26 (9), 663-669. doi:10.1007/ s11655-020-3427-6

WHO (2009). Dengue: Guidelines for Diagnosis, Treatment, Prevention and Control. New Edition. Geneva).

Widener, R. W., and Whitley, R. J. (2014). Herpes Simplex Virus. Handb Clin. Neurol. 123, 251-263. doi:10.1016/B978-0-444-53488-0.00011-0

Wilsky, S., Sobotta, K., Wiesener, N., Pilas, J., Althof, N., Munder, T., et al. (2012). Inhibition of Fatty Acid Synthase by Amentoflavone Reduces Coxsackievirus B3 Replication. Arch. Virol. 157 (2), 259-269. doi:10.1007/s00705-011-1164-Z

Woo, E. R., Lee, J. Y., Cho, I. J., Kim, S. G., and Kang, K. W. (2005). Amentoflavone Inhibits the Induction of Nitric Oxide Synthase by Inhibiting NF-kappaB Activation in Macrophages. Pharmacol. Res. 51 (6), 539-546. doi:10.1016/ j.phrs.2005.02.002

Woolf, A. D., and Pfleger, B. (2003). Burden of Major Musculoskeletal Conditions. Bull World Health Organ 81 (9), 646-656.

Xu, P., Jiang, E. J., Wen, S. Y., and Lu, D. D. (2014). Amentoflavone Acts as a Radioprotector for Irradiated V79 Cells by Regulating Reactive Oxygen Species (ROS), Cell Cycle and Mitochondrial Mass. Asian Pac. J. Cancer Prev. 15 (18), 7521-7526. doi:10.7314/apjcp.2014.15.18.7521

Yao, H., Han, X., and Han, X. (2014). The Cardioprotection of the InsulinMediated PI3K/Akt/mTOR Signaling Pathway. Am. J. Cardiovasc. Drugs 14 (6), 433-442. doi:10.1007/s40256-014-0089-9

Yao, W., Li, H., Liu, Q., Gao, Y., Dai, J., Bao, B., et al. (2016). Cellular Metabolomics Revealed the Cytoprotection of Amentoflavone, a Natural Compound, in Lipopolysaccharide-Induced Injury of Human Umbilical Vein Endothelial Cells. Int. J. Mol. Sci. 17 (9), 1. doi:10.3390/ijms17091514

Yen, T. H., Hsieh, C. L., Liu, T. T., Huang, C. S., Chen, Y. C., Chuang, Y. C., et al. (2018). Amentoflavone Induces Apoptosis and Inhibits NF-kb-Modulated Anti-apoptotic Signaling in Glioblastoma Cells. In Vivo 32 (2), 279-285. doi:10.21873/invivo.11235

Yin, D., Li, J., Lei, X., Liu, Y., Yang, Z., and Chen, K. (2014). Antiviral Activity of Total Flavonoid Extracts from Selaginella Moellendorffii Hieron against Coxsackie Virus B3 In Vitro and In Vivo. Evid. Based Complement Alternat Med. 2014, 950817. doi:10.1155/2014/950817

Yu, S., Yan, H., Zhang, L., Shan, M., Chen, P., Ding, A., et al. (2017). A Review on the Phytochemistry, Pharmacology, and Pharmacokinetics of Amentoflavone, a Naturally-Occurring Biflavonoid. Molecules 22 (2), 1. doi:10.3390/ molecules22020299

Zha, X., Xu, Z., Liu, Y., Xu, L., Huang, H., Zhang, J., et al. (2016). Amentoflavone Enhances Osteogenesis of Human Mesenchymal Stem Cells through JNK and P38 MAPK Pathways. J. Nat. Med. 70 (3), 634-644. doi:10.1007/s11418-0160993-1

Zhang, J., Li, A., Sun, H., Xiong, X., Qin, S., Wang, P., et al. (2020). Amentoflavone Triggers Cell Cycle G2/M Arrest by Interfering with Microtubule Dynamics and Inducing DNA Damage in SKOV3 Cells. Oncol. Lett. 20 (5), 168. doi:10.3892/ol.2020.12031

Zhang, J., Liu, Z., Cao, W., Chen, L., Xiong, X., Qin, S., et al. (2014). Amentoflavone Inhibits Angiogenesis of Endothelial Cells and Stimulates Apoptosis in Hypertrophic Scar Fibroblasts. Burns 40 (5), 922-929. doi:10.1016/ j.burns.2013.10.012
Zhang, J., Zhou, J., Zhang, T., Niu, Z., Wang, J., Guo, J., et al. (2019). Facile Fabrication of an Amentoflavone-Loaded Micelle System for Oral Delivery to Improve Bioavailability and Hypoglycemic Effects in KKAy Mice. ACS Appl. Mater. Inter. 11 (13), 12904-12913. doi:10.1021/acsami.9b03275

Zhang, Z., Sun, T., Niu, J. G., He, Z. Q., Liu, Y., and Wang, F. (2015). Amentoflavone Protects Hippocampal Neurons: Anti-inflammatory, Antioxidative, and Antiapoptotic Effects. Neural Regen. Res. 10 (7), 1125-1133. doi:10.4103/1673-5374.160109

Zhang, Z., Zhao, S., Li, X., Zhuo, X., Zhang, W., Nie, Q., et al. (2018). Amentoflavone Inhibits Osteoclastogenesis and Wear Debris-Induced Osteolysis via Suppressing NF-Kb and MAPKs Signaling Pathways. Planta Med. 84 (11), 759-767. doi:10.1055/s-0043-124594

Zhao, J., Xu, Y., Wang, C., Ding, Y., Chen, M., Wang, Y., et al. (2017a). Soluplus/ TPGS Mixed Micelles for Dioscin Delivery in Cancer Therapy. Drug Dev. Ind. Pharm. 43 (7), 1197-1204. doi:10.1080/03639045.2017.1304956

Zhao, N., Sun, C., Zheng, M., Liu, S., and Shi, R. (2019). Amentoflavone Suppresses Amyloid $\beta$ 1-42 Neurotoxicity in Alzheimer's Disease through the Inhibition of Pyroptosis. Life Sci. 239, 117043. doi:10.1016/j.lfs.2019.117043

Zhao, X., Liu, B., Liu, S., Wang, L., and Wang, J. (2017b). Anticytotoxin Effects of Amentoflavone to Pneumolysin. Biol. Pharm. Bull 40 (1), 61-67. doi:10.1248/ bpb.b16-00598

Zhaohui, W., Yingli, N., Hongli, L., Haijing, W., Xiaohua, Z., Chao, F., et al. (2018). Amentoflavone Induces Apoptosis and Suppresses Glycolysis in Glioma Cells by Targeting miR-124-3p. Neurosci. Lett. 686, 1-9. doi:10.1016/ j.neulet.2018.08.032

Zheng, X., Ke, Y., Feng, A., Yuan, P., Zhou, J., Yu, Y., et al. (2016). The Mechanism by Which Amentoflavone Improves Insulin Resistance in HepG2 Cells. Molecules 21 (5), 1. doi:10.3390/molecules21050624

Zhou, P., Yang, X. L., Wang, X. G., Hu, B., Zhang, L., Zhang, W., et al. (2020). A Pneumonia Outbreak Associated with a New Coronavirus of Probable Bat Origin. Nature 579 (7798), 270-273. doi:10.1038/s41586-020-2012-7

Zong, Y., and Zhang, H. (2017). Amentoflavone Prevents Sepsis-Associated Acute Lung Injury through Nrf2-GCLc-Mediated Upregulation of Glutathione. Acta Biochim. Pol. 64 (1), 93-98. doi:10.18388/abp.2016_1296

Conflict of Interest: The authors declare that the research was conducted in the absence of any commercial or financial relationships that could be construed as a potential conflict of interest.

Publisher's Note: All claims expressed in this article are solely those of the authors and do not necessarily represent those of their affiliated organizations, or those of the publisher, the editors and the reviewers. Any product that may be evaluated in this article, or claim that may be made by its manufacturer, is not guaranteed or endorsed by the publisher.

Copyright (c) 2021 Xiong, Tang, Lai, Zhang, Wen, Li, Li, Wu and Liu. This is an open-access article distributed under the terms of the Creative Commons Attribution License (CC BY). The use, distribution or reproduction in other forums is permitted, provided the original author(s) and the copyright owner(s) are credited and that the original publication in this journal is cited, in accordance with accepted academic practice. No use, distribution or reproduction is permitted which does not comply with these terms. 


\section{ABBREVATIONS}

ACE2 angiotensin-converting enzyme 2

AMF Amentoflavone

AMPK AMP-activated protein kinase

Ask aspartate kinase

ASK1 Apoptosis signal-regulating kinase 1

Bax B-cell lymphoma 2 associated X

Bcl-2 B-cell lymphoma protein-2

BCR B cell receptor

Bid $\mathrm{BH} 3$ interacting-domain death agonist

BMMs bone marrow-derived macrophages

CAT Catalase

CDK1 cyclin-dependent kinase 1

C-FLIP cellular Fasassociated protein with death domain-like interleukin 1 betaconverting enzyme inhibitory protein

COX-2 cyclooxygenase-2

CPA Alpha-toxin

CRP C reactive protein

Cyt-c cytochrome c

EMT epithelial-to-mesenchymal transition

ERK1/2 extracellular regulated protein kinases $1 / 2$

ESR Erythrocyte sedimentation rate

G-6-Pase Glucose-6-phosphatase

GCK Glucokinase

GPx glutathione peroxidase

GSK-3 Glycogen synthase kinase-3

HB Haemoglobin

HO-1 Hemeoxygenase 1

HMGB1 high mobility group box 1

iNOS inducible nitric oxide synthase

IL-1 $\beta$ Interleukin $1 \beta$

IL-6 Interleukin-6
IL-8 Interleukin-8

IC50 inhibitory concentration 50\%

JNK1/2 Jun N-terminal protein kinase 1 and 2

mTOR mammalian target of rapamycin

MAPK mitogen-activated protein kinase

MCL-1 myeloid cell leukemia sequence 1

MDA malondialdehyde

MMP-2 matrix metalloproteinase 2

MMP-9 matrix metalloproteinase 2

MMP mitochondrial membrane potential

MPTP methyl-4-phenyl-1,2,3,6-tetrahydropyridine

NF- $\mathbf{k B}$ nuclear factor $\kappa \mathrm{B}$

NO nitric oxide

NLRP3 nucleotide oligomerization domain-like receptor protein 3

Nrf2 Nuclear factor erythroid 2-related factor 2

PARP poly (adenosine diphosphate-ribose) polymerase

PEPCK Phosphoenolpyruvate carboxylase kinase; PFK-1:6-

Phosphofructokinase

PFO perfringolysin $\mathrm{O}$

PGE2 Prostaglandin E2

PI3K Phosphatidyl inositol 3-kinase

PK Pyruvate kinase

PMNs polymorphonuclear neutrophils

PPAR $\gamma$ peroxisome proliferator-activated receptor $\gamma$

ROS reactive oxygen species

RNS reactive nitrogen species

SOCS3 suppressor of cytokine signaling 3

SOD superoxide dismutase

TNF- $\boldsymbol{\alpha}$ tumor necrosis factor $\boldsymbol{\alpha}$

TNFAIP2 tumor necrosis factor alpha-induced protein 2

uPA urokinasetype plasminogen actvator

UGM uridine diphosphogalactofuranose (UDP)-galactopyranose mutase

VEGF vascular endothelial growth factor 